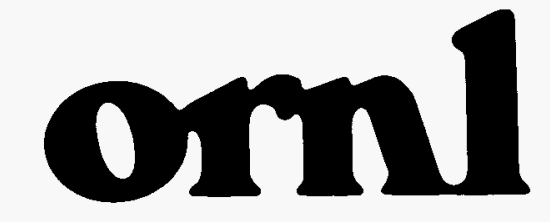

OAK RIDGE NATIONAL LABORATORY

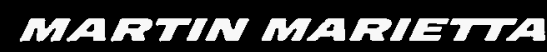

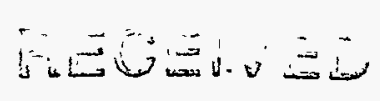

FEB 271996

$\odot$ STI

\title{
Assessment of Aluminum Structural Materials for Service Within the ANS Reflector Vessel
}

\author{
K. Farrell
}

August 1995

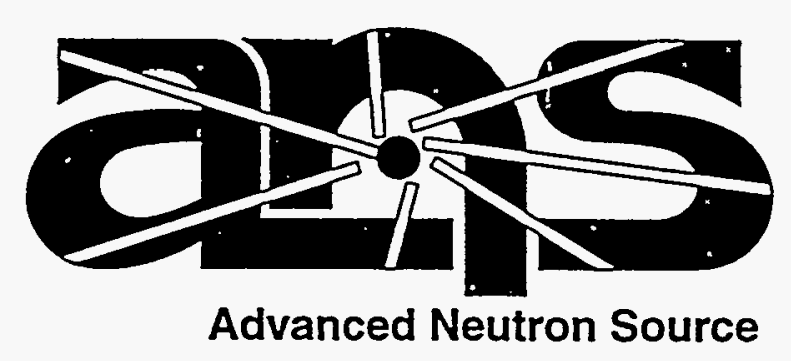

\section{MANAGED BY}

MARTIN MARIETTA ENERGY SYSTEMS, INC. FOR THE UNITED STATES DEPARTMENT OF ENERGY 


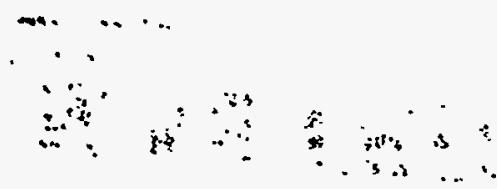

This report has been reproduced directly from the best available copy.

Available to DOE and DOE contractors from the Otfice of Scientific and Technical Information, P.O. Box 62, Oak Ridge, TN 37831; prices available from (615) 576-8401, FTS 626-8401.

Available to the public from the National Technical Information Sorvice, U.S. Department of Commerce, 5285 Port Royal Rd., Springfield, VA 22181.

This report was prepared as an account of work sponsored by an agency of the United States Government. Neither the United States Government nor any agency thereof, nor any of their employees, makes any warranty, express or implied, or assumes any legal liability or responsibility for the accuracy, completeness, or usefulness of any information, apparatus, product, or process disclosed, or represents that its use would not infringe privately owned rights. Reference herein to any specific commercial product, process, or service by trade name, trademark, manufacturer, or otherwise, does not necessarily constitute or imply its endorsement, recommendation, or favoring by the United States Government or any agency thereof. The views and opinions of authors expressed herein do not necessarily state or reflect those of the United States Government or any agency thereof. 
OAK RIDGE NATIONAL LABORATORY

mareTh maknetra
FEB 271936

$$
\Theta S T I
$$

K. Farrell

August 1995

\section{Assessment of Aluminum Structural Materials for Service Within the ANS Reflector Vessel}

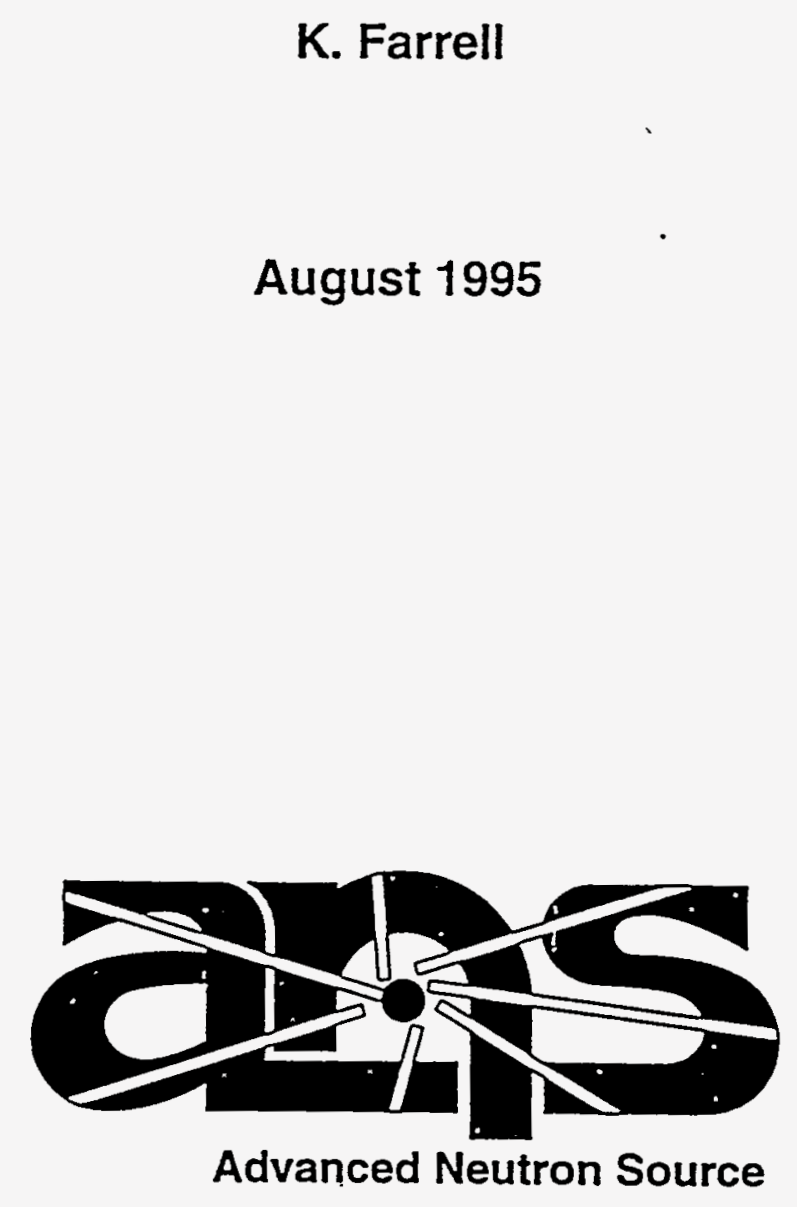

MANAGED BY

MARTIN MARIETTA ENERGY SYSTEMS, INC.

FOR THE UNITED STATES

MASTER 


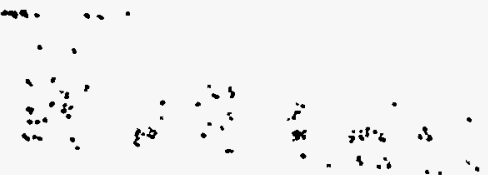

This report has been reproduced directly from the best available copy.

Available to DOE and DOE contractors from the Office of Scientific and Technical Information, P.O. Box 62, Oak Ridge, TN 37831; prices available from (615) 576-8401, FTS 626-8401.

Available to the public from the National Technical Information Sorvice, U.S. Department of Commerce, 5285 Port Royal Rd., Springtield, VA 22161.

This report was prepared as an account of work sponsored by an agency of the United States Government. Neither the United States Government nor any agency thereof, nor any of their employees, makes any warranty, express or implied, or assumes any legal liability or responsibility for the accuracy, completeness, or usefulness of any information, apparatus, product, or process disclosed, or represents that its use would not infringe privately owned rights. Reference herein to any specific commercial product, process, or service by trade name, trademark, manufacturer, or otherwise, does not necessarily constitute or imply its endorsement, recommendation, or favoring by the United States Government or any agency thereol. The views and opinions of authers expressed herein do not necessarily state or reflect those of the United States Government or any agency thereof. 



\title{
ASSESSMENT OF ALUMINUM STRUCTURAL MATERIALS FOR SERVICE WITHIN THE ANS REFLECTOR VESSEL
}

\author{
K. Farrell
}

Date Published: August 1995

\section{DISCLAIMER}

This report was prepared as an account of work sponsored by an agency of the United States Government. Neither the United States Government nor any agency thereof, nor any of their employees, makes any warranty, express or implied, or assumes any legal liability or responsibility for the accuracy, completeness, or usefulness of any information, apparatus, product, or process disclosed, or represents that its use would not infringe privately owned rights. Reference herein to any specific commercial product, process, or service by trade name, trademark, manufacturer, or otherwise does not necessarily constitute or imply its endorsement, recommendation, or favoring by the United States Government or any agency thereof. The views and opinions of authors expressed herein do not necessarily state or reflect those of the United States Government or any agency thereof.

\section{Prepared by}

OAK RIDGE NATIONAL LABORATORY

Oak Ridge, Tennessee 37831-6285

managed by

LOCKHEED MARTIN ENERGY SYSTEMS, INC.

For the

U.S. DEPARTMENT OF ENERGY

under contract DE-AC05-OR21400
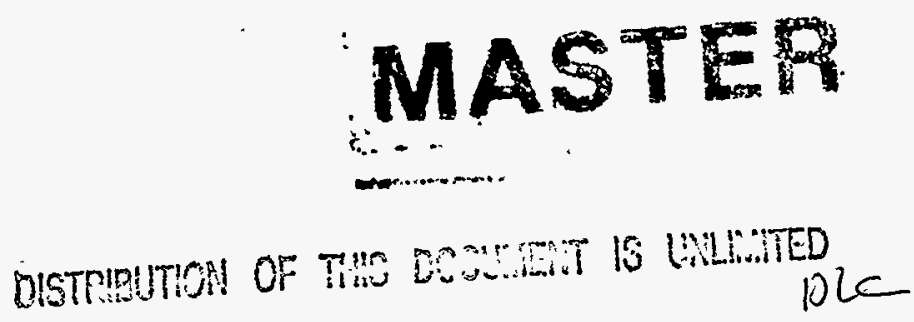



\section{CONTENTS}

LIST OF FIGURES $\ldots \ldots \ldots \ldots \ldots \ldots \ldots \ldots \ldots \ldots \ldots \ldots \ldots \ldots \ldots \ldots \ldots \ldots$

ACRONYMS $\ldots \ldots \ldots \ldots \ldots \ldots \ldots \ldots \ldots \ldots \ldots \ldots \ldots \ldots \ldots \ldots \ldots \ldots \ldots \ldots \ldots$ vii

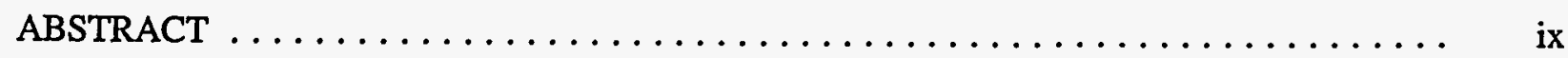

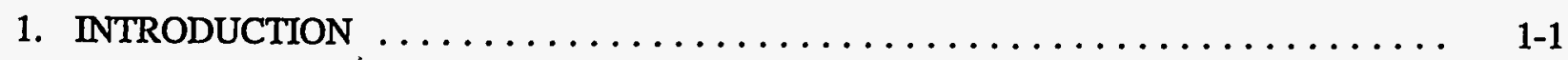

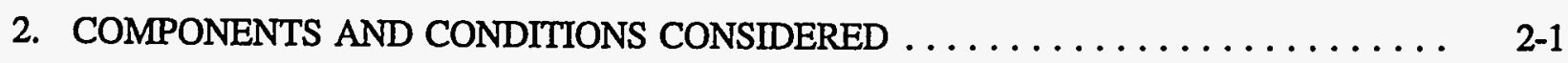

3. CHARACTERISTICS OF UNIRRADIATED 6061-T6 ALUMINUM ALLOY ....... 3-1 3.1 RELEVANCE TO REFERENCE ANS SERVICE CONDITIONS .......... $3-6$

4. RADIATION EXPOSURES AND EFFECTS $\ldots \ldots \ldots \ldots \ldots \ldots \ldots \ldots \ldots \ldots \ldots, 4,1$

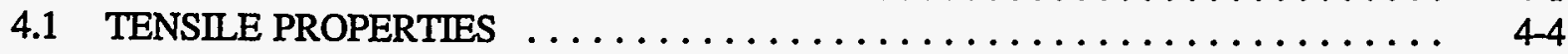

4.2 FRACTURE TOUGHNESS $\ldots \ldots \ldots \ldots \ldots \ldots \ldots \ldots \ldots \ldots \ldots \ldots \ldots, 4,4$

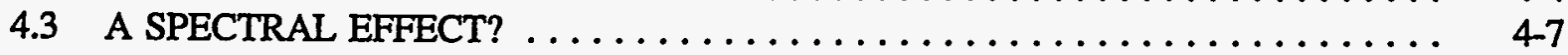

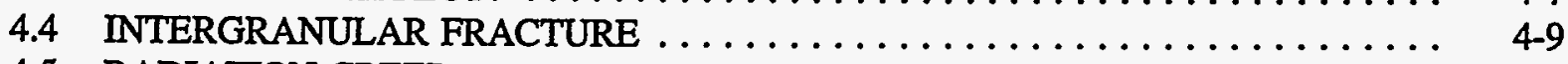

4.5 RADIATION CREEP $\ldots \ldots \ldots \ldots \ldots \ldots \ldots \ldots \ldots \ldots \ldots \ldots \ldots \ldots \ldots \ldots \ldots, 4,10$

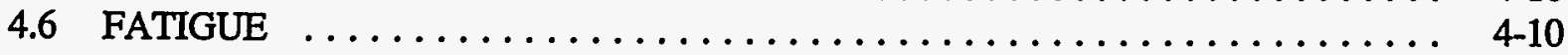

4.7 LOW TEMPERATURES $\ldots \ldots \ldots \ldots \ldots \ldots \ldots \ldots \ldots \ldots \ldots \ldots, 4,11$

$4.8 \quad$ SWELLING $\ldots \ldots \ldots \ldots \ldots \ldots \ldots \ldots \ldots \ldots \ldots \ldots \ldots \ldots \ldots \ldots, 4,12$

4.9 RADIATION SOFTENING $\ldots \ldots \ldots \ldots \ldots \ldots \ldots \ldots \ldots \ldots \ldots \ldots \ldots, 4,12$

4.10 EFFECTS OF GAMMA RAYS $\ldots \ldots \ldots \ldots \ldots \ldots \ldots \ldots \ldots \ldots \ldots \ldots \ldots, 4,15$

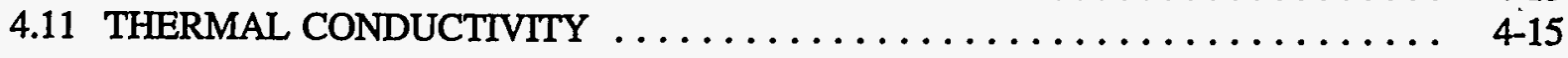

5. ASSESSMENT OF ANS REACTOR COMPONENTS ............... 5-1

5.1 CONTROL ROD FOLLOWERS AND IN-CORE MATERIALS

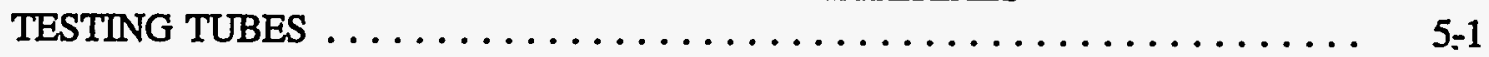

5.2 CORE PRESSURE BOUNDARY TUBE $\ldots \ldots \ldots \ldots \ldots \ldots \ldots \ldots \ldots \ldots$ 5-1

5.3 HYDRAULIC TUBES HT-2 AND -4 AND SH-1 AND $-2 \ldots \ldots \ldots \ldots \ldots \ldots .5,2$

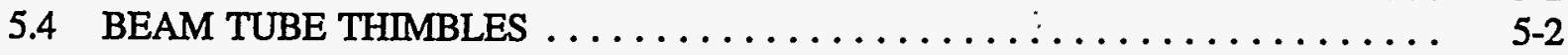

5.5 COLD SOURCE THIMBLES $\ldots \ldots \ldots \ldots \ldots \ldots \ldots \ldots \ldots \ldots \ldots \ldots \ldots \ldots, 5,3$

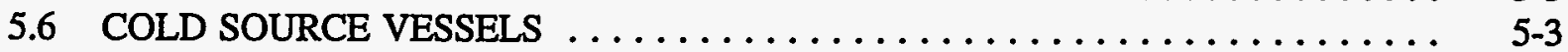

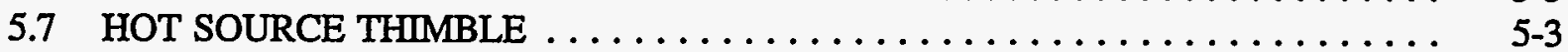

5.8 HYDRAULIC TUBES HT- 1 and $-3 \ldots \ldots \ldots \ldots \ldots \ldots \ldots \ldots \ldots \ldots \ldots \ldots, 5-4$

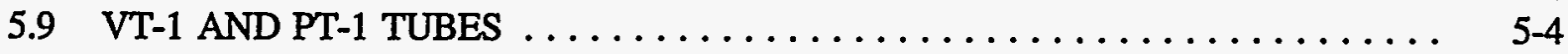

5.10 THE REFLECTOR VESSEL $\ldots \ldots \ldots \ldots \ldots \ldots \ldots \ldots \ldots \ldots \ldots \ldots, 5,4$

5.11 SHUTDOWN ROD GUIDES $\ldots \ldots \ldots \ldots \ldots \ldots \ldots \ldots \ldots \ldots \ldots \ldots \ldots \ldots \ldots, 5-4$

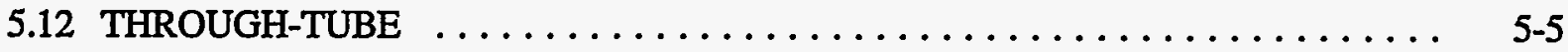

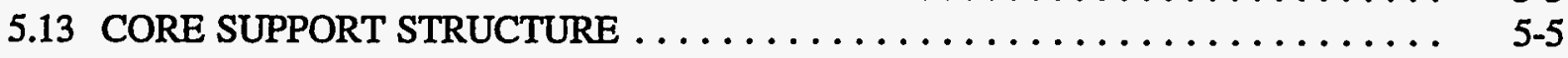

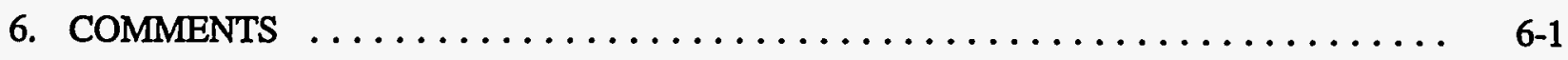

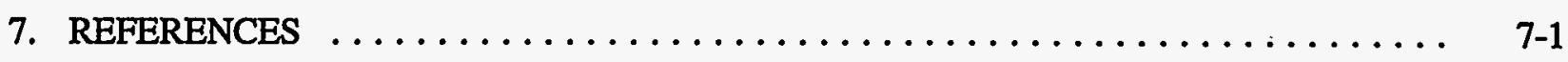





\section{LIST OF FIGURES}

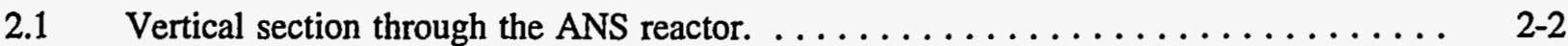

2.2 Horizontal section through the reactor at core midplane. . . . . . . . . . . $2-3$

3.1 Needle-like precipitates of $\mathrm{Mg}_{2} \mathrm{Si}$ phase in unirradiated $6060-\mathrm{T} 6$ alloy. . . . . . . . 3-2

3.2 Effects of temperature, time, and stress on the mechanical strength and ductility of unirradiated $6061-\mathrm{T} 6$ alloy in air. . . . . . . . . . . . . . . . $3-3$

3.3 Creep and stress relaxation properties of $6061-\mathrm{T} 6$ alloy. . . . . . . . . . . . .

4.1 Cycle-averaged radial fluxes at core midplane. . . . . . . . . . . . . $4-2$

4.2 Cycle-averaged axial flux profiles at 430 -mm radius. . . . . . . . . . . . $4-3$

4.3 Effects of ratio of thermal to fast flux on fractions of atomic displacements produced by fast, epithermal, and thermal neutrons. .............. 4-5

4.4 Room temperature tensile properties of 6061-T6 and 6061-T651 aluminum alloy after neutron irradiation at temperatures $<100^{\circ} \mathrm{C} . \ldots \ldots \ldots \ldots \ldots \ldots$

4.5 Fracture toughness of 6061-T6 and 6061-T651 after neutron irradiation at temperatures $<100^{\circ} \mathrm{C} . \ldots \ldots \ldots \ldots \ldots \ldots \ldots \ldots \ldots \ldots \ldots$. . . . . . . . . . . . . .

4.6 Swelling in neutron-irradiated aluminum alloys $\ldots \ldots \ldots \ldots \ldots \ldots \ldots \ldots \ldots$ 



\section{ACRONYMS}

\begin{tabular}{|c|c|}
\hline ANS & Advanced Neutron Source \\
\hline ASME & American Society of Mechanical Engineers \\
\hline CPBT & core pressure boundary tube \\
\hline dpa & displacements per atom \\
\hline FMD & freely migrating defect \\
\hline HFBR & High Flux Beam Reactor \\
\hline HFIR & High Flux Isotope Reactor \\
\hline MT & materials testing \\
\hline ORNL & Oak Ridge National Laboratory \\
\hline RHF & Reacteur Haut Flux \\
\hline RV & reflector vessel \\
\hline TEM & transmission electron microscopy \\
\hline UTS & ultimate tensile strength \\
\hline YS & yield strength \\
\hline
\end{tabular}


: 


\begin{abstract}
Most of the components in the Advanced Neutron Source (ANS) reactor, including the reflector vessel, will be built from the aluminum alloy $6061(1 \mathrm{Mg}, 0.6 \mathrm{Si})$ in its precipitation-hardened $\mathrm{T} 6$ and T651 conditions. The microstructural and mechanical characteristics of the alloy are described, and its operating boundaries of stress, temperature, and time in its unirradiated state are defined. The material's responses to neutron radiation exposure in aqueous environments are reviewed in detail. The particular service conditions of stress, temperature, and radiation exposure expected for individual components in the ANS are listed, and the suitability of each component to meet the demands is assessed. Areas of uncertainties are outlined, and various suggestions and recommendations are made to give improved confidence in the predictions.
\end{abstract}





\section{INTRODUCTION}

The Advanced Neutron Source (ANS) is conceived as a new user facility for all types of neutron research. ${ }^{1}$ The source of neutrons is a $330-\mathrm{MW}$ (fission) research reactor designed to produce the world's most intense flux of thermal neutrons, $-7 \times 10^{19} \mathrm{~m}^{-2} \cdot \mathrm{s}^{-1}$. The 6061 aluminum alloy in its T6 or T651 condition has been selected as the primary structural material for the reactor's reflector vessel (RV) and for most of the components housed within the vessel. The deciding factors were the alloy's good combination of low neutron absorption cross section and high thermal conductivity, good resistance to aqueous corrosion, and demonstrated dependability during service in other high flux reactors, notably the High Flux Beam Reactor (HFBR) at Brookhaven National Laboratory and the High Flux Isotope Reactor (HFIR) at Oak Ridge National Laboratory (ORNL). This report describes the characteristics of the 6061-T6 alloy and examines its fitness for service in the wide range of radiation conditions that will prevail at and within the ANS RV. The emphasis is on the changes in mechanical properties expected to occur in the components under irradiation during their intended lifetimes. The purpose is to anticipate potential problems and to identify components and conditions for which service effects considerations might suggest modifications in the reactor design. 


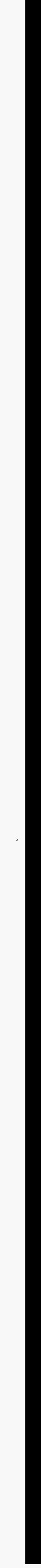




\section{COMPONENTS AND CONDITIONS CONSIDERED}

A vertical section through the ANS is seen in Fig. 2.1. The core is fueled by enriched uranium and is cooled, moderated, and reflected by heavy water. It comprises two annular fuel elements of different diameters, positioned one above the other on a common vertical cylindrical axis and enclosed by a double-walled tube known as the core pressure boundary tube (CPBT), which reaches from top to bottom of the RV and whose function is to channel a rapid flow of heavy water coolant up through the fuel elements. The coolant at $45^{\circ} \mathrm{C}$ enters the bottom of the CPBT through a flanged, stainless steel adapter that connects the CPBT to the bottom of the RV and to the externally located primary coolant supply manifold. The coolant, exiting at $85^{\circ} \mathrm{C}$, leaves the top of the CPBT through a closure elbow bolted to the head of the RV and connected to the primary coolant outlet pipe. The CPBT is surrounded by heavy water reflector retained in the cylindrical $R V$, which has a radius of $1.75 \mathrm{~m}$ and is $-4.1 \mathrm{~m}$ tall. The RV is immersed in a pool of light water.

At the core horizontal centerline, ten large beam tubes penetrate the RV and approach the CPBT, as shown in plan view in Fig. 2.2. Their domed tips impinge on a circle of 430-mm radius from the core axial centerline, near the region of peak thermal flux. Seven of these beam tubes, HB-1 through HB-3 and HB-6 through HB-9, and one through-tube, HB-5/HB-10, which is located below the horizontal centerline, are for the extraction of thermal neutrons. These beam tubes are elliptical in cross section, with the long axes of the ellipses in the vertical plane, and will be referred to collectively as "thermal beam tubes." Two larger, tapered tubes, CS-1 and CS-2, are sources of cold neutrons and contain hollow aluminum spheres filled with liquid deuterium at $-253^{\circ} \mathrm{C}$. A source of hot neutrons, HB-4, houses a ball of graphite sealed in a vessel of Zircaloy. The graphite will operate at a temperature of $-2270^{\circ} \mathrm{C}$. Numerous, top-entry, small-diameter, terminated aluminum tubes (VT-, HT-, PT-, and SH- series) pierce the top of the RV in vertical and slant orientations and reach down into the reflector. Additionally, and not shown in Fig. 2.2, there are ten vertical terminated tubes for materials testing inside the upper fuel element, herein designated the MT- series. As a whole, these top-entry tubes provide facilities for materials irradiation, neutron activation analyses, and production of isotopes and transuranium elements. They will be referred to collectively as "vertical tubes."

The reactor is controlled by three primary control and shutdown rods of hafnium in the center of the core, and there are eight secondary shutdown rods of hafnium distributed uniformly around the outside of the CPBT. The three control rods are supported on aluminum control drive follower tubes; in their withdrawn positions, the control rods are located above the core. The eight shutdown rods are suspended above the core from inside the top of the RV in stationary, aluminum guide tubes.

The components considered in this report are the CPBT, the RV, the thermal beam tubes, the cold source vessels and thimbles, the hot source thimble, the vertical tubes, the control rod follower tubes, the shutdown rod driver tubes, and the core support components. All of these will be fabricated from 6061-T6 or -T651 aluminum alloy. The aluminum-clad fuel elements are not considered in this study. 


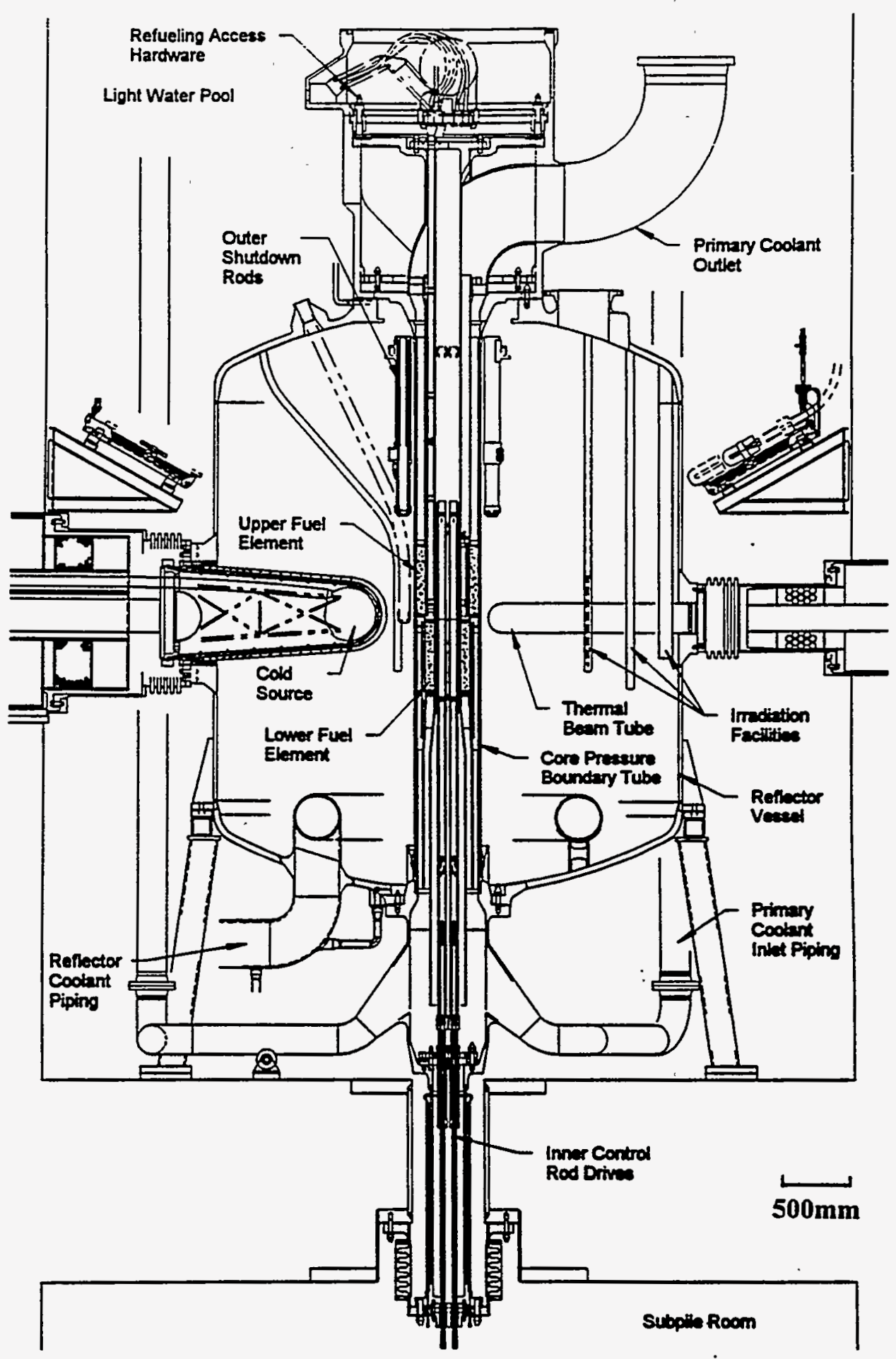

Fig. 2.1. Vertical section through the ANS reactor. 


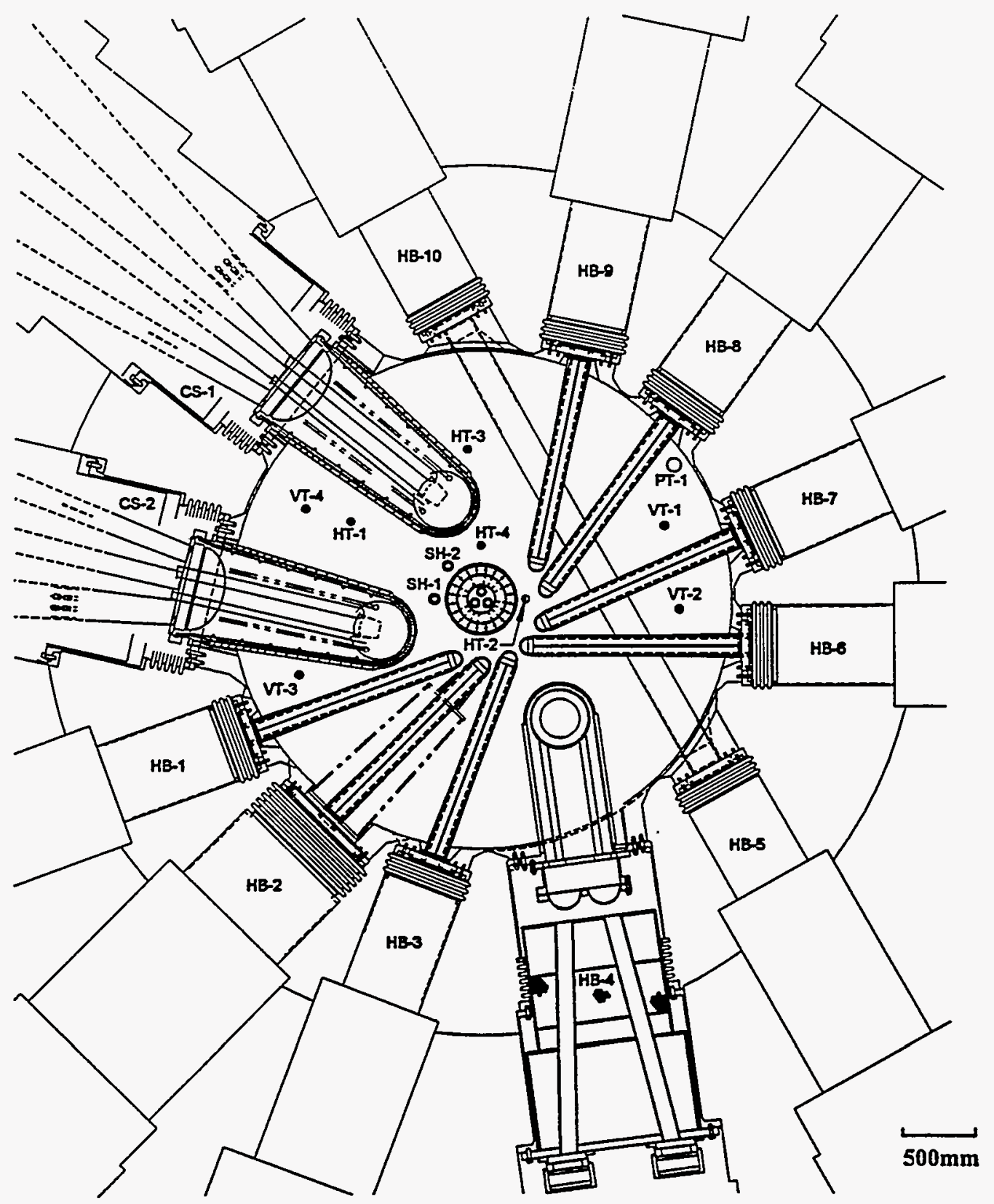

Fig. 2.2. Horizontal section through the reactor at core midplane. 



\section{CHARACTERISTICS OF UNIRRADIATED 6061-T6 ALUMINUM ALLOY}

Before considering the service conditions expected for the reactor components, it is instructive to understand the characteristics of unirradiated 6061 aluminum alloy, particularly its stress and temperature limitations. The 6000 -series aluminum alloys have magnesium and silicon as their major alloying elements. The 6061 alloy contains $0.8-1.2 \mathrm{wt} \% \mathrm{Mg}$ and 0.4-0.8 wt \% Si. Additionally, small quantities ( $<0.3$ wt \% each ) of $\mathrm{Fe}, \mathrm{Cu}, \mathrm{Cr}, \mathrm{Ti}$, and $\mathrm{Zn}$ are present, some of which are claimed to be essential for grain size control, improved aqueous corrosion resistance, and mechanical strength maintenance. Good combinations of strength and ductility are obtained in 6061 alloy by heat treating it to induce a finely distributed precipitate of $\mathrm{Mg}_{2} \mathrm{Si}$ phase. Strengthening by heat treatment is practical because $\mathrm{Mg}$ and $\mathrm{Si}$ are quite soluble in aluminum at temperatures above $-400^{\circ} \mathrm{C}$, but $\mathrm{Si}$ is essentially insoluble below about $200^{\circ} \mathrm{C}$. Therefore, $\mathrm{Si}$ and $\mathrm{Mg}$ can be taken into solid solution by heating the alloy to an elevated temperature then cooling rapidly, and the $\mathrm{Mg}_{2} \mathrm{Si}$ phase can be brought out by reheating to a temperature below about $200^{\circ} \mathrm{C}$. The particular heat treatment for the $\mathrm{T} 6$ condition consists of annealing at $532^{\circ} \mathrm{C}$ for $1 \mathrm{~h}$, quenching in water to room temperature, then aging (tempering) at $160^{\circ} \mathrm{C}$ for $18 \mathrm{~h}$ to precipitate the $\mathrm{Mg}_{2} \mathrm{Si}$ phase. The resulting microstructure is displayed in Fig. 3.1. The strength of the alloy is dependent on the fineness of the $\mathrm{Mg}_{2} \mathrm{Si}$ precipitate particles. Aging at higher temperature or holding at higher temperature after aging at $160^{\circ} \mathrm{C}$ will coarsen the precipitates and correspondingly reduce the strength of the alloy. The T651 temper designation indicates material that has been given a straightening treatment after the quench and prior to the aging treatment. Despite this extra treatment, the properties of T651 and T6 remain close, and they share the same specifications.

These details of the heat treatment are described to draw attention to a limitation of precipitationhardened alloys. Namely, they are thermodynamically unstable, and to a large extent their aging temperature defines an upper boundary to their service temperature. For 6061-T6 alloy, short exposures above $160^{\circ} \mathrm{C}$ or prolonged periods just below $160^{\circ} \mathrm{C}$ will degrade its mechanical strength by overaging the $\mathrm{Mg}_{2} \mathrm{Si}$ phase. ${ }^{2,3}$ These effects are illustrated in Fig. 3.2 where the curves depict the temperature dependencies of the tensile yield stress (YS) at $0.2 \%$ offset, the ultimate tensile strength (UTS), and the total elongation. The effects of holding without load at the test temperature for periods up to $10,000 \mathrm{~h}$ following the T6 heat treatment are displayed. Two important conclusions are evident from study of Fig. 3.2.

The first conclusion is that at temperatures above $150^{\circ} \mathrm{C}$, the $\mathrm{T} 6$ alloy suffers loss in strength, the deterioration increasing with time at temperature. Above $200^{\circ} \mathrm{C}$, the weakening is considerable, and there is a corresponding gain in ductility. A small part of this weakening arises from the normal, thermally assisted overcoming of barriers to plastic flow. But the major portion of the loss in strength is caused by coarsening of the $\mathrm{Mg}_{2} \mathrm{Si}$ precipitates. Because this overaging increases substantially with time spent at the elevated temperature, the load limits that a 6061-T6 component can tolerate will be dictated by the required service period. The second conclusion is that most of the weakening induced by exposure to elevated temperature is permanent. The loss in strength is not recovered when the material is returned to a lower temperature. This phenomenon is illustrated by the example of material tested at $25^{\circ} \mathrm{C}$ after heating for $1 / 2 \mathrm{~h}$ at $315^{\circ} \mathrm{C}$. The extent to which this permanent softening can go is given by the properties for the fully annealed alloy, $6061-\mathrm{O}\left(2 \mathrm{~h}\right.$ at $\left.413^{\circ} \mathrm{C}\right)$.

Another important feature of aluminum alloys is that they are susceptible to creep and stress relaxation. Creep is a time-dependent, permanent deformation that occurs under sustained load or stress, even at stresses below the yield strength. For the most part, creep is governed by migration of vacant lattice sites, which increases with temperature. For most metallic materials, vacancy migration is sufficient for creep when the temperature exceeds about $0.3 T_{m}$, where $T_{m}$ is the melting temperature 


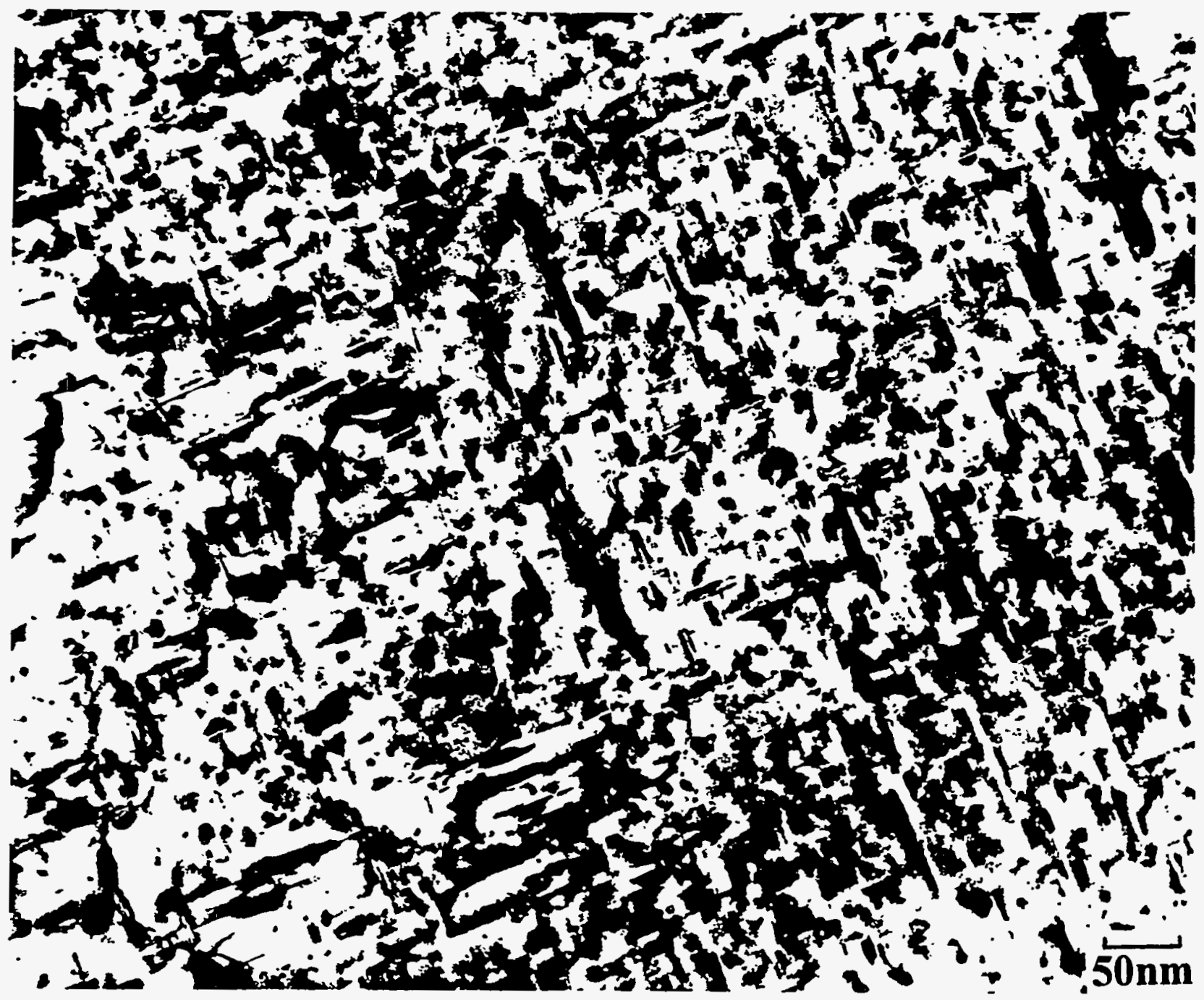

Fig. 3.1. Needle-like precipitates of $\mathrm{Mg}_{2} \mathrm{Si}$ phase in unirradiated 6061-T6 alloy. 

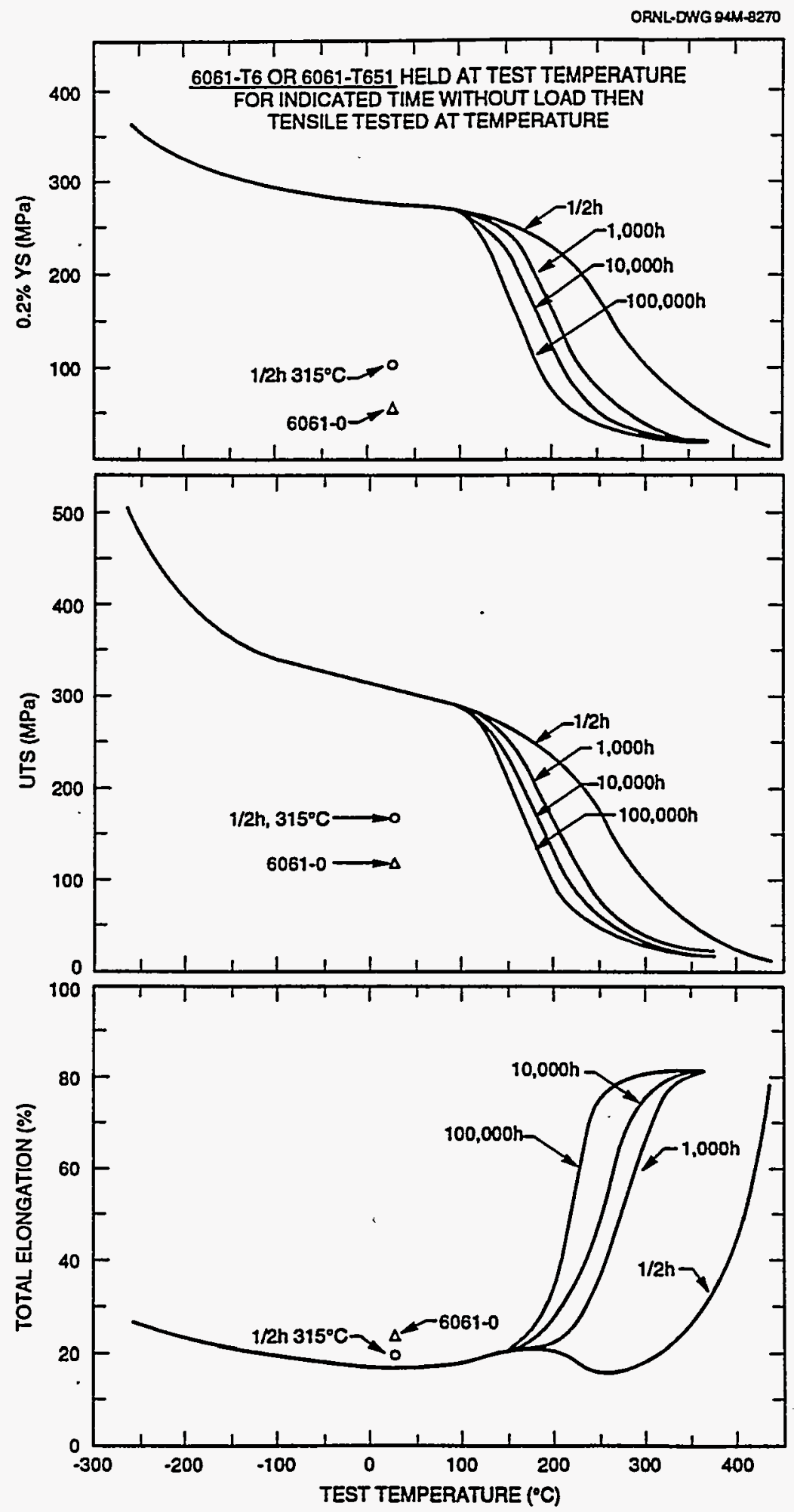

Fig. 3.2. Effects of temperature, time, and stress on the mechanical strength and ductility of unirradiated 6061-T6 alloy in air. 
of the material on the absolute scale. For aluminum, with its low melting temperature of $659^{\circ} \mathrm{C}$, a homologous temperature of $0.3 \mathrm{~T}_{\mathrm{m}}$ is only $7^{\circ} \mathrm{C}$. Hence, creep can and does occur in pure aluminum at room temperature. The $6061-\mathrm{T} 6$ alloy is more creep resistant. Nevertheless, at $150^{\circ} \mathrm{C}$, which is the upper end of the range of operating temperatures for some of the ANS components, the homologous temperature is $0.45 \mathrm{~T}_{\mathrm{m}}$, and creep in 6061-T6 alloy can be substantial. Some creep data ${ }^{3-5^{*}}$ are shown in relation to a $100,000-\mathrm{h}$ no-load plot of UTS versus test temperature in Fig. 3.3. It is clear that degradation of the strength of the alloy is accelerated by the application of tensile stress. In Fig. 3.3, the 100,000 -h stress-rupture data are obtained from Ref. 5 by making modest extrapolations of the data; as such, they should be regarded as only a guide to the upper stress limits for creep rupture in $100,000 \mathrm{~h}$.

Stress relaxation is a form of creep in which deformation is constrained but stress is relieved by converting elastic strain to plastic strain. Once the stress is released, further strain ceases. Stress relaxation is particularly pertinent to fasteners, which lose their holding ability as stress is relaxed. Stress relaxation data for type 6061-T651 alloy, loaded in tension to $60 \%$ or more of the yield strength at the test temperature, ${ }^{6,7}$ are represented by the upward curving line in Fig. 3.3. Some stress relaxation is evident at $100^{\circ} \mathrm{C}$, and almost $30 \%$ relaxation occurs in $1000 \mathrm{~h}$ at $150^{\circ} \mathrm{C}$. Although there will be no 6061 aluminum fasteners in the components covered in this assessment, ANS designers are considering the feasibility of a CPBT reinforced with 6061 wire wrapping; the wrapping may be susceptible to stress relaxation.

A very positive feature of aluminum alloys is that they do not suffer a ductile-to-brittle transition at low temperatures. This is evident for the $6061-\mathrm{T} 6$ alloy in Fig. 3.2. Below $-100^{\circ} \mathrm{C}$, the strength of the alloy increases significantly, but the ductility rises. Aluminum alloys are also not very sensitive to strain rate. This fortunate combination of properties causes increased fracture toughness at low temperatures. A very recent review of fracture toughness properties of $6061-\mathrm{T} 6$ alloy ${ }^{8}$ places the mean value of $K_{I c}$ (and $K_{q}$ and $K_{j}$ ) at $-33 \mathrm{Mpa} \sqrt{m}$ at room temperature for L-T and T-L crack orientations and at $-30 \mathrm{Mpa} \sqrt{\mathrm{m}}$ at $150^{\circ} \mathrm{C}$. Fracture toughness values in S-L orientations are approximately $2 / 3$ of the $\mathrm{L}-\mathrm{T}$ values. At $-196^{\circ} \mathrm{C}, \mathrm{K}_{\mathrm{Ic}}$ is $-40 \mathrm{Mpa}{ }_{\mathrm{m}}{ }^{8,9}$ which, together with high thermal conductivity, makes the alloy an attractive candidate for cryogenic applications, ${ }^{10}$ hence its proposed role for the ANS cold sources. Welding treatments severely reduce the strength of 6061-T6 alloy but do not seem to have corresponding adverse effects on fracture toughness.

Like other materials, aluminum alloys are susceptible to cyclic fatigue. The most recent summary of fatigue data for 6061-T6 alloy ${ }^{11}$ indicates that for uniaxial and biaxial loading with full reversal of stress (i.e., zero mean stress), the fatigue strength at $10^{8}-10^{9}$ cycles is about $50 \mathrm{Mpa}$ for temperatures less than $150^{\circ} \mathrm{C}$. With maximum mean stress, the fatigue strength is about $20 \mathrm{Mpa}$. For welds, these values are reduced by a factor of 2 . At cryogenic temperatures the values are approximately doubled.

The 6061 alloy is regarded as one of the more readily weldable alloys. It can be fusion welded by most of the common welding techniques using appropriate cover gases. Filler metal containing magnesium and silicon is usually incorporated. During welding, the T6 alloy loses its temper and hence its strength. Porosity induced by welding may be a problem.

The thermal conductivity of $6061-\mathrm{T} 6$ aluminum at $25^{\circ} \mathrm{C}$ is about $170 \mathrm{~W} \cdot \mathrm{m}^{-1} \cdot \mathrm{K}^{-1}$, which is about ten times that for stainless steel and Zircaloy. Its aqueous corrosion resistance is high, especially in slightly acidified water in the $\mathrm{pH}$ range 4.5-7.0. Corrosion rates are increased at higher temperatures. Chloride ions are deleterious.

Includes unpublished information courtesy of the Aluminum Company of America. 
ORNL-DWG 94M-8272R

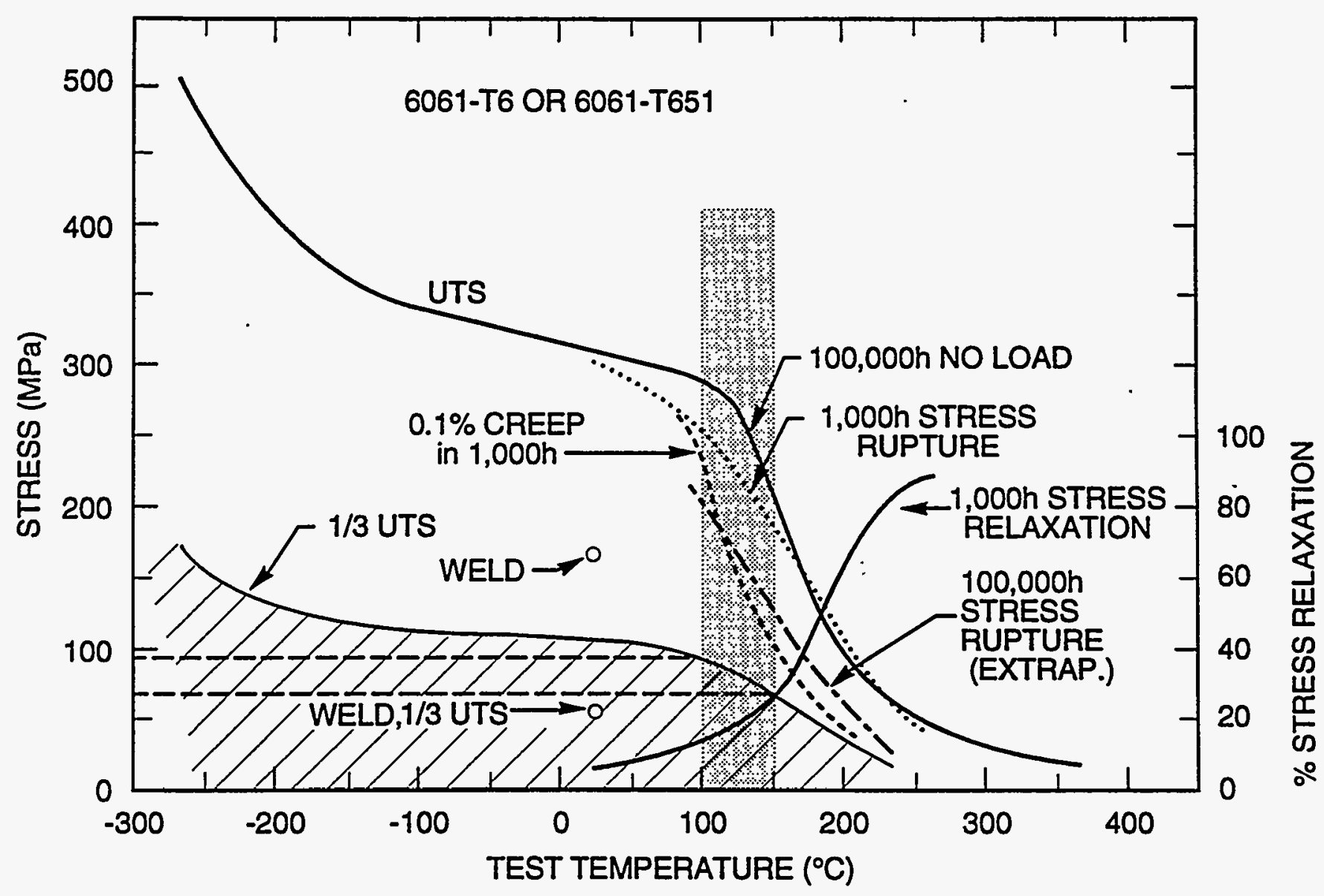

Fig. 3.3. Creep and stress relaxation properties of 6061-T6 alloy. 


\subsection{RELEVANCE TO REFERENCE ANS SERVICE CONDITIONS}

The presently envisioned service conditions for ANS components are listed in Table 3.1. Note the expected temperatures, stresses, and component lifetimes. Many of the temperatures are in the range $100-150^{\circ} \mathrm{C}$, with stress levels of $20-150 \mathrm{MPa}$ for periods of 3,500-245,000 h. The stresses and temperatures are the peak values (e.g., the temperature at the midthickness of the wall of a component) and, therefore, do not represent bulk values, which will be lower. For want of better guidance, the quoted peak values are regarded as the upper limits of working stresses and temperatures for the components. They are generally higher than those experienced by 6061-T6 alloy in the HFBR and the HFIR. They are high because the much higher power density and neutron fluxes in the ANS cause correspondingly more neutron and gamma heating than in the HFBR and the HFIR, entailing greater coolant flows and pressures and larger temperature gradients and thermal stresses. Aluminum components in the HFBR and the HFIR operate at $<100^{\circ} \mathrm{C}$ (closer to $60^{\circ} \mathrm{C}$ ), which, in terms of homologous temperature, is considerably lower than $150^{\circ} \mathrm{C}$. With respect to stresses, the highest stress in the HFBR is a circumferential stress of $61 \mathrm{MPa}$ in the 6061-T6 pressure vessel;" on the beam tubes, the stresses are compressive at a maximum of $15 \mathrm{MPa}$. In the HFIR, the pressure vessel is steel; the highest stress sustained by an aluminum component is a low compressive stress on the smalldiameter hydraulic rabbit tube. ${ }^{\dagger}$ So the HFIR and HFBR experiences with 6061-T6 alloy offer no guidance to performance at the stresses and temperatures expected in the ANS. Such guidance will have to be drawn from sources like the data in Figs. 3.2 and 3.3, which have provided the basis for recent approval of an American Society of Mechanical Engineers (ASME) Code Case for use of 6061T6 aluminum alloy for nuclear pressure vessels at temperatures not exceeding $149^{\circ} \mathrm{C} .^{12}$

Under the regulations of ASME Boiler and Pressure Vessel Code, Sect. IV, Appendix 2, Part D, the permissible stress levels are defined as the least value of either two-thirds of the tensile YS or onethird of the UTS at the service temperature. These criteria are for materials with stable microstructures. To apply them to the unstable 6061-T6 alloy for ANS components, the time-degraded strengths should be used. For 6061-T6 alloy, the one-third UTS criterion has the least stress values, which are shown by the cross-hatched region in Fig. 3.3. This principle confines the design stresses at $100^{\circ} \mathrm{C}$ and $150^{\circ} \mathrm{C}$ to $95 \mathrm{MPa}$ and $70 \mathrm{MPa}$, respectively. The peak stresses on several of the components in Table 3.1, namely the control rod followers, the CPBT, the shutdown rod guides, and perhaps the RV, are approaching or exceeding these design limit values. The stresses and temperatures in the table are tentative and may be reduced as more sophisticated calculations are made. However, the ceiling values might move downwards, too, because of the influence of two factors that are not covered adequately in the ASME code. One is creep. If creep is likely to be involved, the ASME code suggests that stresses be limited to the lowest of the following:

1. $100 \%$ of the average stress to produce a creep rate of $0.01 \%$ in $1000 \mathrm{~h}$,

2. $67 \%$ of the average stress to cause rupture in $100,000 \mathrm{~h}$, or

3. $80 \%$ of the minimum stress to cause rupture in $100,000 \mathrm{~h}$.

Creep data for T6 and T651 alloy, summarized in Fig. 3.3, indicate that the stress values for option 2 are higher than the stress limits set by the one-third UTS criterion; those for option 3 are likely to be higher, too. But option 1 might be invoked. The available creep data contain insufficient information

"P. Tichler, Brookhaven National Laboratory, personal communication to the author, April 1994.

'R.B. Rothrock, Oak Ridge National Laboratory, personal communication to the author, 1994. 
Table 3.1. Goal service conditions

\begin{tabular}{|c|c|c|c|c|c|c|c|c|c|c|c|c|c|c|c|c|c|}
\hline \multirow{2}{*}{ Component } & \multicolumn{2}{|c|}{ Location } & \multicolumn{5}{|c|}{ Fluxes $\left(m^{-2} \cdot s^{-1}\right)^{b}$} & \multirow{2}{*}{$\begin{array}{c}\text { Nuclear } \\
\text { heating } \\
\text { rate } \\
\text { (W/g) }\end{array}$} & \multirow{2}{*}{$\begin{array}{l}\text { Peak } \\
\text { temp. } \\
\text { (०C) }^{\circ}\end{array}$} & \multirow{2}{*}{$\begin{array}{l}\text { Peak } \\
\text { stress } \\
\text { (MPa) }\end{array}$} & \multirow{2}{*}{$\begin{array}{c}\text { Goal } \\
\text { life } \\
\text { (years) }\end{array}$} & \multirow{2}{*}{$\begin{array}{l}\text { Thermald } \\
\text { fluence } \\
\left(n / m^{2}\right)\end{array}$} & \multirow{2}{*}{$\begin{array}{l}\text { Ratio } \\
\phi_{d} / \phi_{r}\end{array}$} & \multirow{2}{*}{$\begin{array}{l}\text { Ratiof } \\
\phi / \phi_{r}\end{array}$} & \multirow{2}{*}{$\mathrm{dpa}^{2}$} & \multirow{2}{*}{$\stackrel{\mathscr{6}}{\mathrm{dpa}^{n}{ }^{n}}$} & \multirow{2}{*}{$\begin{array}{l}\mathrm{Si}^{I} \\
\text { (wt \%) }\end{array}$} \\
\hline & $\underset{(\mathrm{mm})}{R}$ & $\underset{(\mathrm{mm})}{Z}$ & Fast & Epi 1 & Epi 2 & Thermal & Gamma & & & & & & & & & & \\
\hline Control rod followers & 48 & 0 & $1.2 \times 10^{19}$ & $3.9 \times 10^{19}$ & $2.3 \times 10^{19}$ & $2.4 \times 10^{19}$ & $7.3 \times 10^{18}$ & 34.3 & $>100 ?$ & 90 & 2.0 & $1 \times 10^{77}$ & 2 & 0.6 & 72 & 0.4 & 1.9 \\
\hline In-core MT tubes & 122 & 0 & $1.8 \times 10^{19}$ & $4.1 \times 10^{19}$ & $2.0 \times 10^{19}$ & $1.5 \times 10^{19}$ & $8.5 \times 10^{12}$ & 40.6 & $?$ & $?$ & 2.0 & $6 \times 10^{23}$ & 1 & 0.5 & 105 & 0.2 & 1.2 \\
\hline CPBT & 250 & 0 & $1.3 \times 10^{19}$ & $2.7 \times 10^{19}$ & $1.4 \times 10^{19}$ & $3.7 \times 10^{19}$ & $6.5 \times 10^{11}$ & 35.1 & 105 & $92-96$ & 0.5 & $5 \times 10^{23}$ & 3 & 0.5 & 23 & 0.6 & 0.9 \\
\hline HT-2 & 310 & 0 & $4.2 \times 10^{18}$ & $1.5 \times 10^{19}$ & $1.1 \times 10^{19}$ & $6.1 \times 10^{19}$ & $3.4 \times 10^{11}$ & 29.7 & $120-150$ & 20 & 2.0 & $3 \times 10^{37}$ & 15 & 1 & 26 & 2.7 & 5.5 \\
\hline SH-1, -2 & 330 & 0 & $2.9 \times 10^{12}$ & $1.1 \times 10^{19}$ & $9.5 \times 10^{18}$ & $6.5 \times 10^{19}$ & $2.9 \times 10^{13}$ & 28.6 & $120-150$ & 20 & 2.0 & $3 \times 10^{27}$ & 22 & 1 & 19 & 4.0 & 5.9 \\
\hline HT-4 & 380 & o & $1.4 \times 10^{11}$ & $6.9 \times 10^{11}$ & $6.8 \times 10^{12}$ & $7.0 \times 10^{19}$ & $2.2 \times 10^{13}$ & 26.2 & 125 & 44 & 2.0 & $3 \times 10^{27}$ & 50 & 1 & 10 & 7.6 & 6.4 \\
\hline Beam tube thimbles & 430 & 0 & $5.2 \times 10^{17}$ & $3.0 \times 10^{12}$ & $3.8 \times 10^{11}$ & $6.9 \times 10^{19}$ & $1.5 \times 10^{12}$ & 22.7 & 125 & 44 & 2.0 & $3 \times 10^{27}$ & 130 & 3 & 4 & 19 & 6.4 \\
\hline Cold source thimbles & 493 & 0 & $2.0 \times 10^{17}$ & $1.2 \times 10^{11}$ & $2.0 \times 10^{18}$ & $6.5 \times 10^{19}$ & $1.0 \times 10^{11}$ & 19.3 & 125 & 42 & 2.0 & $3 \times 10^{27}$ & 330 & 5 & 2 & 36 & 6.0 \\
\hline Cold source vessels & 750 & $\mathbf{0}$ & $4.9 \times 10^{13}$ & $2.6 \times 10^{16}$ & $6.2 \times 10^{16}$ & $3.9 \times 10^{19}$ & $2.9 \times 10^{11}$ & 9.7 & -253 & 50 & 2.0 & $2 \times 10^{x}$ & $8 \times 10^{3}$ & 60 & 0.5 & 93 & 3.6 \\
\hline Hot source thimble & 750 & 0 & $4.9 \times 10^{15}$ & $2.6 \times 10^{16}$ & $6.2 \times 10^{16}$ & $3.9 \times 10^{19}$ & $2.9 \times 10^{17}$ & 9.7 & 125 & 50 & 2.0 & $2 \times 10^{37}$ & $8 \times 10^{3}$ & 60 & 0.5 & 93 & 3.6 \\
\hline HT $-1,-3$ & 1064 & 0 & $2.3 \times 10^{14}$ & $6.9 \times 10^{14}$ & $9.5 \times 10^{14}$ & $2.0 \times 10^{19}$ & $8.7 \times 10^{16}$ & 4.6 & -100 & $?$ & 2.0 & $9 \times 10^{25}$ & $8 \times 10^{4}$ & 370 & 0.2 & 99.4 & 1.8 \\
\hline VT-1, $-2,-3,-4$ & 1384 & 0 & $9.0 \times 10^{13}$ & $2.3 \times 10^{14}$ & $1.8 \times 10^{14}$ & $9.3 \times 10^{11}$ & $4.7 \times 10^{16}$ & 2.2 & -100 & $?$ & 2.0 & $4 \times 10^{25}$ & $1 \times 10^{5}$ & 520 & 0.1 & 99.4 & 0.9 \\
\hline PT-1 & 1650 & 0 & $1.1 \times 10^{14}$ & $2.5 \times 10^{14}$ & $1.5 \times 10^{14}$ & $3.7 \times 10^{11}$ & $7.5 \times 10^{16}$ & 1.0 & -100 & $?$ & 2.07 & $2 \times 10^{25}$ & $3 \times 10^{4}$ & 660 & 0.05 & 98.5 & 0.4 \\
\hline $\begin{array}{l}\text { Reflector vessel: } \\
\text { Sidewall }\end{array}$ & 1750 & o & $8.5 \times 10^{13}$ & $1.3 \times 10^{14}$ & $8.2 \times 10^{13}$ & $1.8 \times 10^{11}$ & $1.7 \times 10^{17}$ & 0.66 & 125 & $100 ?$ & 40.0 & $1.6 \times 10^{27}$ & $2 \times 10^{4}$ & $2 \times 10^{3}$ & 0.5 & 97.8 & 3.3 \\
\hline Top at flange & 512 & 2057 & $3.0 \times 10^{13}$ & $5.6 \times 10^{13}$ & $4.0 \times 10^{13}$ & $5.2 \times 10^{17}$ & $6.3 \times 10^{16}$ & 0.24 & 125 & $100 ?$ & 40.0 & $5 \times 10^{28}$ & $2 \times 10^{4}$ & $2 \times 10^{3}$ & 0.1 & 97.5 & 0.9 \\
\hline Bottom at flange & 433 & -2057 & $4.6 \times 10^{13}$ & $8.9 \times 10^{13}$ & $6.7 \times 10^{13}$ & $6.9 \times 10^{17}$ & $8.8 \times 10^{16}$ & 0.30 & 125 & $100 ?$ & 40.0 & $6 \times 10^{26}$ & $2 \times 10^{4}$ & $2 \times 10^{3}$ & 0.2 & 96.8 & 1.3 \\
\hline Shutdown rod guides & 330 & 800 & $5.9 \times 10^{16}$ & $3.8 \times 10^{11}$ & $5.8 \times 10^{11}$ & $1.9 \times 10^{19}$ & $7.8 \times 10^{17}$ & 6.6 & $120-150$ & 90 & 2.0 & $8 \times 10^{3}$ & 320 & 13 & 0.6 & 35 & 1.8 \\
\hline Through-tube & 700 & -300 & $6.3 \times 10^{15}$ & $3.4 \times 10^{16}$ & $8.3 \times 10^{16}$ & $4.0 \times 10^{19}$ & $3.3 \times 10^{17}$ & 10.5 & 125 & 50 & 2.0 & $1.8 \times 10^{37}$ & $6.4 \times 10^{3}$ & 52 & 0.6 & 93 & 3.9 \\
\hline Core supports & 140 & -680 & $1.2 \times 10^{18}$ & $5.8 \times 10^{11}$ & $5.3 \times 10^{11}$ & $3.7 \times 10^{19}$ & $2.3 \times 10^{12}$ & 14.8 & $<100$ & 40 & 0.5 & $5 \times 10^{26}$ & 30 & 2 & 2 & 5 & 0.9 \\
\hline
\end{tabular}

Coordinates $\mathrm{R}$ (radius) and $\mathrm{Z}$ (height) are referenced to he midpol $00.1 \mathrm{MeV}$; epithermal flux 2 is $0.625 \mathrm{eV}<\mathrm{E}<100 \mathrm{eV}$; thermal flux is $\mathrm{E}<0.625 \mathrm{eV}$; gamma flux is $\mathrm{E}>2 \mathrm{MeV}$.

Nuclear heating rate is sum of neutron and gamma heating rates.

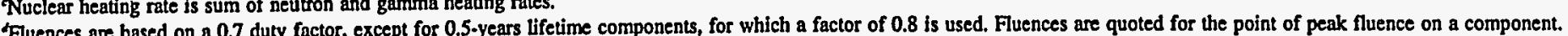

Fatio of thermal flux to fast flux.

Radio of gamma flux $>2 \mathrm{MeV}$ to fast flux.

Total displacements per atom.

tPercentage of total displacements contributed by thermal neutrons.

'Silicon generated by transmutations. 
to allow determination of the stress levels that will cause a creep rate of $0.01 \%$ in $1000 \mathrm{~h}$. Secondary creep rates are given, but primary creep rates and levels are often not published. Neglect of primary creep, which typically occurs at a faster rate than secondary creep, will give nonconservative stress levels under option 1 . It can be assumed that the stresses for $0.01 \%$ creep in $1000 \mathrm{~h}$ will be less than those shown in Fig. 3.3 for $0.1 \%$ creep in $1000 \mathrm{~h}$, meaning that, at $150^{\circ} \mathrm{C}$ at least, the unknown stress levels of option 1 may become decisive.

The other factor inadequately covered in the ASME code is the effects of environment. The data base for the 6061 alloy code case was obtained by tests performed in air. The ANS components will operate in water. It is well known that a water environment generally has a degrading effect on metals. In particular, fatigue life can be significantly reduced in aqueous media. The effects on other mechanical properties are less quantified. One consequence of exposure of aluminum to air or water is the formation of surface oxide films that can retard removal of nuclear heat from components, raising their temperatures and thereby reducing the tolerable stress levels. This latter aspect has been considered elsewhere, and the temperature increases appear to be insignificant for the ANS components.

Another reason for avoiding temperatures above $150^{\circ} \mathrm{C}$, which has already been addressed in the preliminary ANS design, is the decline in fracture toughness with increasing temperature. The plane strain fracture toughness of 6061-T6 alloy is modest at best, and any substantial reduction is undesirable. The alloy also has a low tearing modulus, implying that if a crack does get initiated, it may propagate readily. Hence, maximum resistance to cracking requires the lowest achievable temperatures.

The overaging response of 6061-T6 alloy at elevated temperatures means that the alloy cannot tolerate upward temperature excursions during service; even a short period at a temperature above $200^{\circ} \mathrm{C}$ may render the alloy unfit to support its service load when returned to its normal operating temperature. The worst nonservice temperature excursion is welding. The precipitation-hardened condition is destroyed during welding; consequently, the mechanical strength of weldments will be inferior to that of the base material. An example ${ }^{3}$ of weld strength is given in Fig. 3.3. The strength is roughly half that of the unwelded alloy. Some degree of degradation will extend through the heataffected zones on each side of the weld, typically to distances of two to three times the width of the weld fusion zone. ${ }^{13}$ Partial relief is available by postweld aging, which restores some strength at the risk of reducing the strength of the base material. The use of autogenous welds eliminates filler materials and offers the possibility of full restoration of properties by allowing a complete reheat treatment of the welded component. Residual porosity from the weld process and distortion from quenching during heat treatment may cause problems. The best policy is to avoid welds wherever possible. Welds will be required in some ANS components, and it is recognized in their designs that the degraded properties of the welds will determine the permissible stress levels on components.

Recommendation \#1: In view of the described degrading effects of temperature, time, and stress and the uncertain effects of water environment and creep on the long-term mechanical properties of unirradiated 6061-T6 alloy, design efforts should continue towards reducing the stresses, operating temperatures, or assigned lifetimes of the more highly stressed components. 


\section{RADIATION EXPOSURES AND EFFECTS}

The reactor will operate on a $21-\mathrm{d}$ cycle, $17 \mathrm{~d}$ bum and $4 \mathrm{~d}$ refuel. Calculated, cycle-averaged neutron and gamma flux profiles across the radius of the reactor at the core horizontal midplane are shown in Fig. 4.1. These neutron flux profiles are somewhat different from those appearing in earlier descriptions of the ANS. They are calculated ${ }^{14}$ for recent designs, using the most accurate and complete Monte Carlo models, which include contributions from photoneutrons generated in the $\mathrm{D}_{2} \mathrm{O}$ reflector. These photoneutrons cause the fast and epithermal neutron fluxes to curtail their sharp declines with radial distance. The less-steep radial declines in gamma ray fluxes are reversed near the vessel, where gamma photons emitted from the RV following capture of thermal neutrons boost the local gamma fluxes. The thermal neutron flux peaks at a radius of $-400 \mathrm{~mm}$. Flux profiles in the axial direction at $430-\mathrm{mm}$ radius, corresponding to the locations of the beam tube tips, are given in Fig. 4.2. The profiles in the core region include some perturbation by components there, but the profiles in the reflector regions do not incorporate local fluctuations caused by the presence of structural components in the reflector.

The fluxes seen by the various reactor components are given in Table 3.1 together with their estimated lifetime fluences. These fluxes and fluences will alter the properties of the components. Radiation effects in aluminum at the temperatures of interest are driven primarily by two sources. One is point defects, vacancies, and self-interstitial atoms created when aluminum atoms are displaced from their lattice positions. The other is precipitates of transmutation-produced silicon. The atomic displacements per atom (dpa) and the weight percentages of silicon expected in the various reactor components are listed in the table. To explain their roles briefly, an introduction to the basic elements of radiation effects and a review of the consequences in aluminum now follow.

Atomic displacements are caused predominantly by fast neutrons with energies $>0.1 \mathrm{Mev}$ through their elastic interactions with lattice atoms and consequent knock-on events, resulting in displacement cascades. Much of the energy deposited in a cascade is converted to a momentary heating spike, during which most of the vacancy and interstitial point defects are annihilated by recombination. Those remaining are in the form of freely migrating defects (FMDs) or small clusters of like defects. Some of the FMDs drift around until they are absorbed at sinks such as dislocations, grain boundaries, and precipitates. Diffusion processes are controlled by point defects, and because the point defect concentrations exceed the thermal equilibrium levels, diffusion of atoms is enhanced just as though the metal were at a higher temperature. Solute atoms are swept to the sinks by the flows of FMDs, resulting in solute segregation and phase instability. Creep processes are accelerated. Those FMDs that avoid sinks either encounter unlike defects in the matrix and are recombined or meet similar defects and form clusters. The clusters grow and shrink as they absorb FMDs. Some grow into visible loops that eventually evolve into dislocation lines and tangles. Other clusters capture solute atoms and become precipitate nuclei. Some of the vacancy clusters take up gas atoms that stabilize the cluster as a small bubble. If bubbles reach a critical size, they develop into voids that cause the alloy to swell. Bubbles located on grain boundaries can expand under an applied stress and link to form intergranular cracks at elevated temperatures, a phenomenon known as helium embrittlement. All of these radiationinduced microstructural features present obstacles to the passage of dislocations during mechanical loading and thus harden and embrittle the metal.

Fast neutrons are not the only sources of point defects. They are also created, to lesser degrees, by epithermal neutrons, by high-energy gamma photons, and by atomic recoils in transmutation reactions. The major source of the latter in aluminum are the recoils from the thermal neutron capture reactions that produce silicon. In the regions of the ANS outside the core, the neutron spectrum is highly thermalized, and the generation of point defects in many of the components located in those 
ORNL-DWG 94M-9602

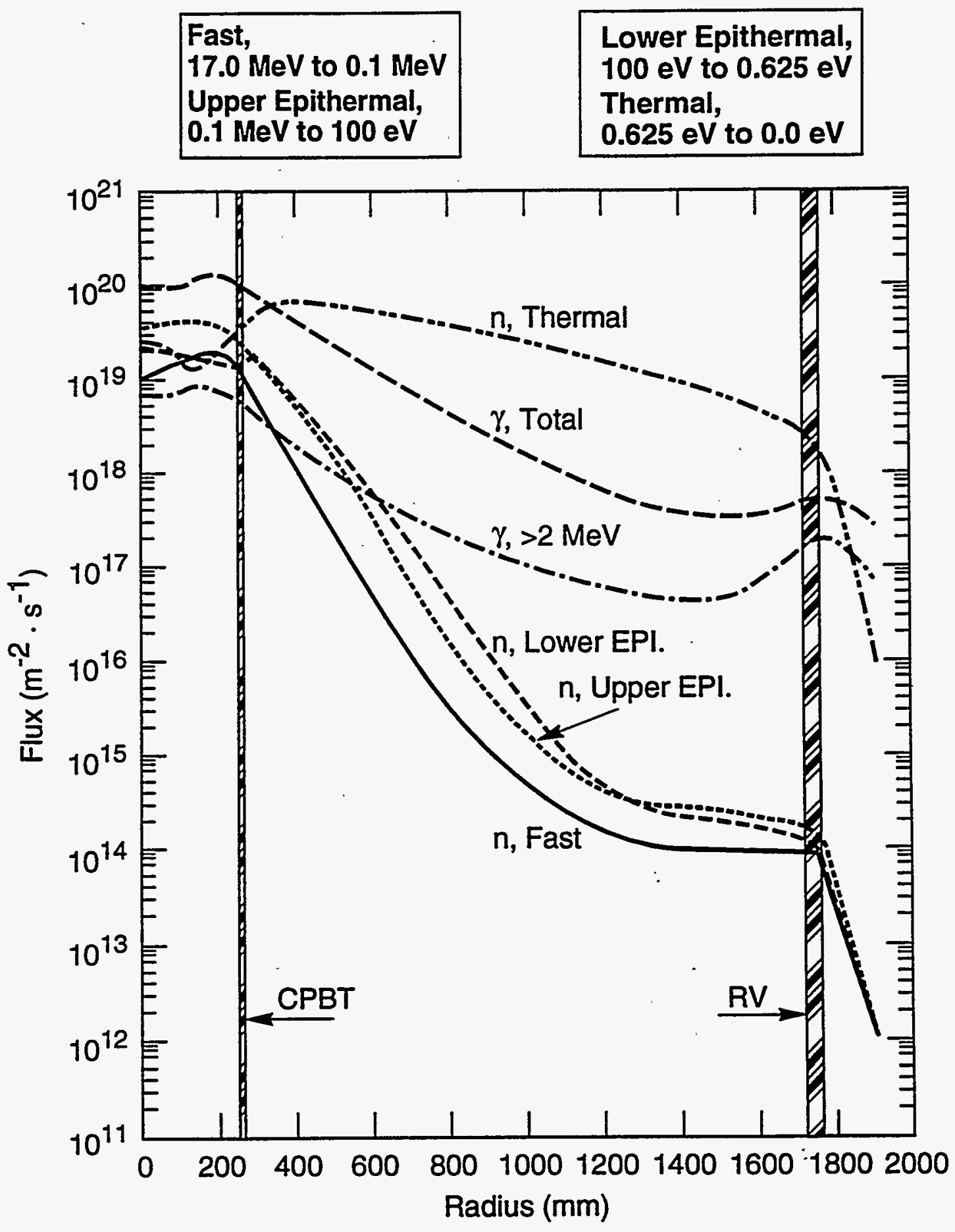

Fig. 4.1. Cycle-averaged radial fluxes at core midplane. 
ORNL-DWG 94M-9604



Fig. 4.2. Cycle-averaged axial flux profiles at $430-\mathrm{mm}$ radius. 
regions will be substantially affected, in some cases dominated, by the thermal neutron flux or fluence. Figure 4.3 illustrates how the relative percentages of dpa in aluminum change with the ratio of thermal flux to fast flux, $\phi_{\mathrm{th}} / \phi_{\mathrm{f}}$. Figure 4.3 was derived using group displacement cross sections ${ }^{*}$ of $1192,64.7$, 0.238 , and $2.73 \mathrm{~b}$ for neutron energies of $>0.1 \mathrm{MeV}, 0.1 \mathrm{MeV}$ to $100 \mathrm{eV}, 100$ to $0.625 \mathrm{eV}$, and $<0.625 \mathrm{eV}$, respectively, appropriate to the ANS spectra. The lower epithermal group makes an almost negligible contribution and is folded into the upper epithermal group for simplicity. It can be seen that the thermal neutrons become the major point defect source when the $\phi_{\mathrm{th}} / \phi_{\mathrm{f}}$ ratio exceeds -400 . The neutron spectrum may also influence the effects of transmutation-produced silicon, of which more will be said shortly.

Transmutation products in aluminum are primarily silicon from reactions with thermal neutrons and hydrogen and helium generated by fast neutrons. Specific cross sections for the $(n, p)$ and $(n, \alpha)$ reactions with aluminum in the ANS spectra are not available but they should be somewhat similar to the respective values of 2.7 and $0.47 \mathrm{mb}$ derived from data for the HFIR target region for neutrons with $E>0.1 \mathrm{MeV} .^{15}$ These cross sections will result in $\sim 160$ appm hydrogen and -28 appm helium in the in-core MT tubes, which are expected to receive the highest fast neutron fluences of all the components over their design lifetime of two years. Silicon is produced in aluminum by capture of thermal neutrons via the reactions ${ }^{27} \mathrm{Al}(\mathrm{n}, \gamma)^{28} \mathrm{Al} \rightarrow{ }^{28} \mathrm{Si}+\beta^{-}$. The cross section varies as $1 / \mathrm{E}$ and has a value of $230 \mathrm{mb}$ for neutrons of energy $2200 \mathrm{~m} / \mathrm{s}(E=0.025 \mathrm{eV})$. The amounts of transmutationproduced silicon expected in the various ANS components are given in the final column of Table 3.1. The largest quantities, about $6.4 \mathrm{wt} \%$, will be generated in the thermal beam tube thimbles. Silicon is insoluble in aluminum at temperatures below $200^{\circ} \mathrm{C}$, and it forms small precipitates. ${ }^{16}$ These precipitates are responsible for most of the radiation strengthening in 6061-T6 alloy. ${ }^{17-21}$

\subsection{TENSILE PROPERTIES}

The effects of radiation on tensile properties are shown in Fig. 4.4 as a function of thermal neutron fluence for $6061-\mathrm{T} 6$ and $-\mathrm{T} 651$ irradiated at $<100^{\circ} \mathrm{C}$ in water or $\mathrm{D}_{2} \mathrm{O}$ and tested at $25-55^{\circ} \mathrm{C}$ in air. These data are compiled from all accessible sources ${ }^{17-26 t}$ and are now registered in Ref. 27 . There is scatter in the data. For safe design purposes, the worst-case effects are the important ones and are depicted by the lines representing the maximum values of yield stress and ultimate strength and the minimum values of total and uniform elongation. These lines conform with the general trends of the data and show that thermal neutron fluences below about $1 \times 10^{25} \mathrm{~m}^{-2}$. have only minor effects on tensile properties. At higher fluences there is continuous strengthening, accompanied by continuous loss in total elongation, but the decline in uniform elongation appears to plateau at 3-4\%. Tests performed at $150^{\circ} \mathrm{C}$ and $200^{\circ} \mathrm{C}$ after high fluence exposure ${ }^{18,19}$ show lower strengths and lower ductilities than $50^{\circ} \mathrm{C}$ tests, with uniform elongations $<1 \%$. The highest fluence data in Fig. 4.4. involve levels of transmutant silicon of 6-9 wt \%. This range is pertinent to the ANS beam tubes and cold source thimbles.

\subsection{FRACTURE TOUGHNESS}

For metals in general, a reduction in tensile ductility is usually accompanied by a reduction in fracture toughness. For $6061-\mathrm{T} 6$ alloy there is no established relationship between fracture toughness

\footnotetext{
"J. A. Bucholz, Oak Ridge National Laboratory, personal communication to the author, May 1994.

tncludes unpublished data from S.T. Mahmood and the author, Oak Ridge National Laboratory, 1993.
} 
ORNL-DWG 94M-9603

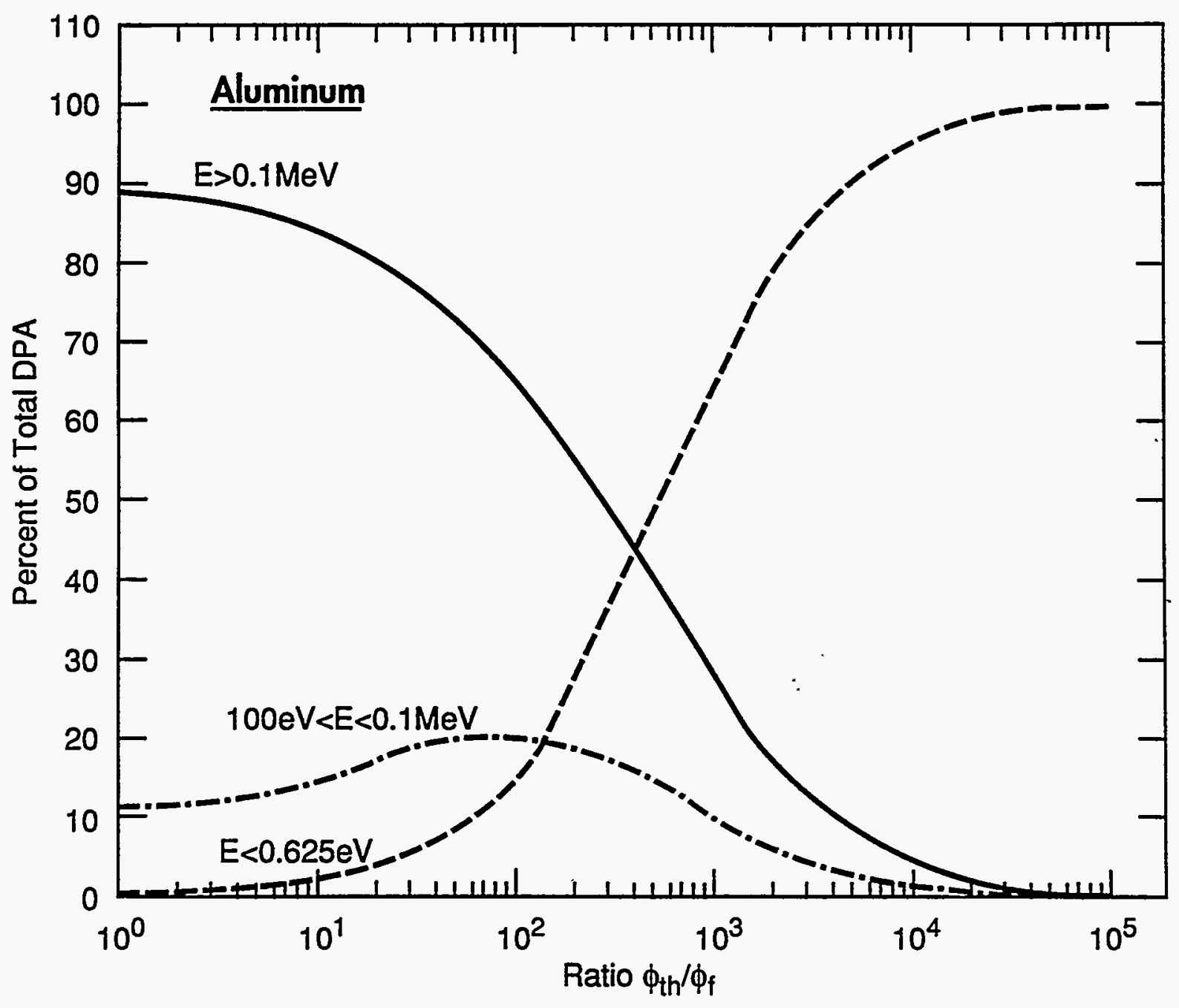

Fig. 4.3. Effects of ratio of thermal to fast flux on fractions of atomic displacements produced by fast, epithermal, and thermal neutrons. 


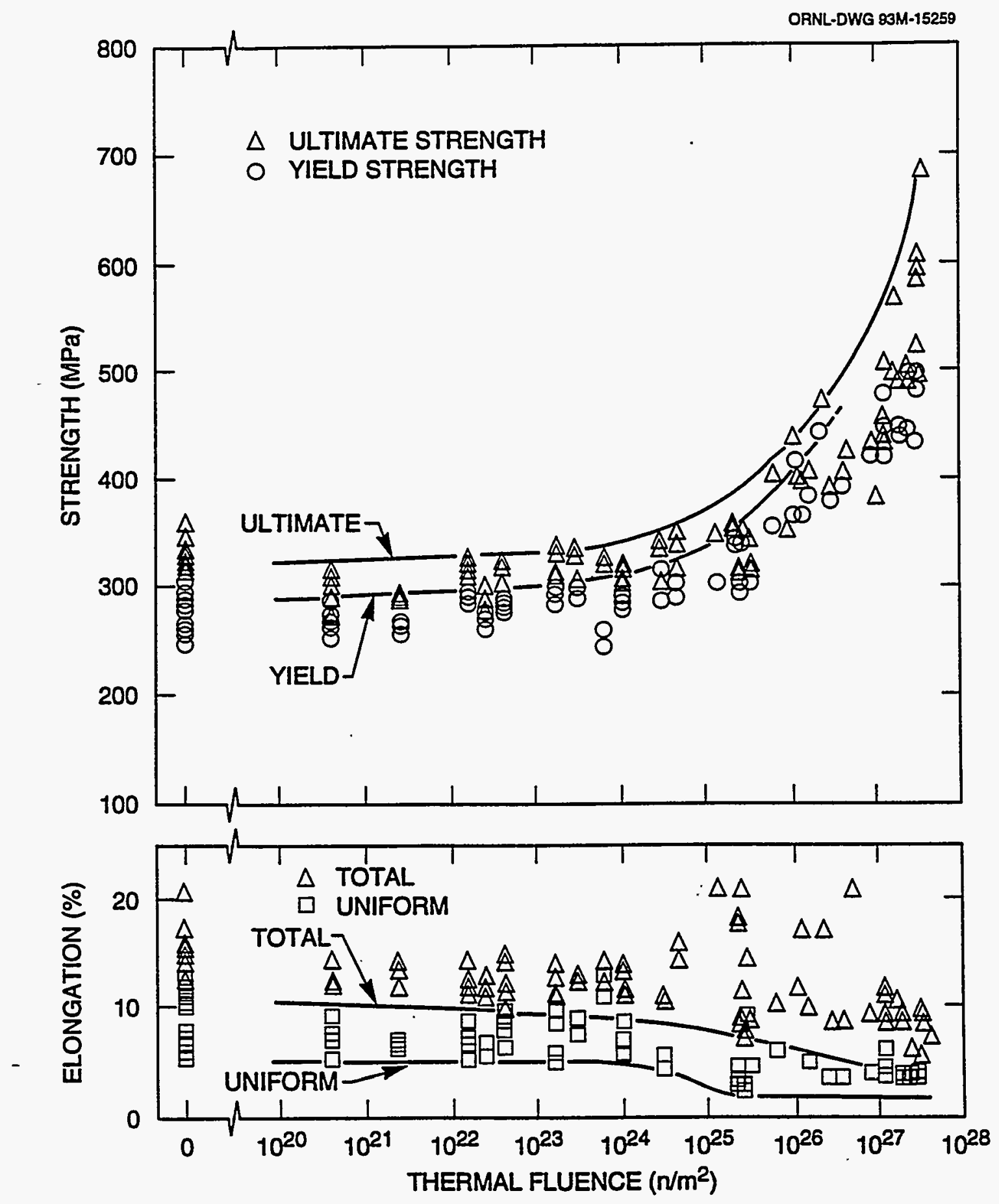

Fig. 4.4. Room temperature tensile properties of 6061-T6 and 6061-T651 aluminum alloy after neutron irradiation at temperatures $<100^{\circ} \mathrm{C}$. 
and tensile properties from which to predict the toughness. The toughness data must be acquired by measurement and are sparse. The results for irradiated 6061-T6 aluminum are displayed in Fig. 4.5. All of these are recent acquisitions. The small numerals alongside the data points represent the $\phi_{\mathrm{u}} / \phi_{\mathrm{f}}$ ratios. The higher the ratio, the softer the spectrum. The data labeled HFIR irradiations are from ongoing ANS experiments ${ }^{26,28}$ conducted to simulate the lifetime exposure of the ANS CPBT. These indicate that the fracture toughness remains unchanged at about $32 \mathrm{Mpa} \sqrt{\mathrm{m}}$ after an exposure to a thermal neutron fluence of $8 \times 10^{26} \mathrm{~m}^{-2}$, which exceeds the planned lifetime exposure of the CPBT. This apparent insensitivity to irradiation prevails despite increases in tensile strength and decreases in tensile ductility predicted by Fig. 4.4 and measured by Alexander. ${ }^{28}$ However, a very low tearing modulus was noted, implying low resistance to crack propagation. Also, the fracture toughness was noticeably reduced in tests made at $150^{\circ} \mathrm{C}$.

The datum point from the HFBR irradiations ${ }^{25}$ in Fig. 4.4 suggests that the fracture toughness may be reduced by $75 \%$ at a thermal neutron fluence of $4 \times 10^{27} \mathrm{~m}^{-2}$ and a $\phi_{\mathrm{th}} / \phi_{\mathrm{f}}$ ratio of 20 . The thermal neutron fluences expected for the thimbles of the ANS thermal beam tubes and cold sources range up to more than $3 \times 10^{27} \mathrm{~m}^{-2}$, and the $\phi_{\mathrm{ut}} / \phi_{\mathrm{f}}$ ratios in the ANS cover a very wide spread of 1 to $10^{5}$. These conditions are denoted by the bar at the bottom of Fig. 4.5. There is some argument that the HFBR data may not be strictly valid. They were not obtained according to rigid linear elastic fracture mechanics rules but rather were estimated from notched tensile test data and from measurements of impact energy made on nonstandard Charpy test pieces cut from retired reactor components. To further confound the issue, the exposure conditions for the HFBR specimens were different from the HFIR irradiations. They involved much longer times at lower fluxes and in softer spectra. Some intergranular fracture facets were evident on the broken surfaces of the HFBR specimens. There are strong signs that longer exposure times, softer spectra, and the involvement of intergranular fracture may accentuate radiation damage, as discussed in following sections. Thus, it is conceivable that the low fracture toughness at high dose may be less an artifact of the unconventional route by which it was obtained than a genuine consequence of the different exposure conditions.

The only other fracture toughness data at ambient temperature for an irradiated aluminum alloy were obtained for $5154\left(\mathrm{Al}-3.5 \% \mathrm{Mg}\right.$ ) alloy. ${ }^{29}$ Conditional $\mathrm{K}_{\mathrm{IQ}}$ values were $-28 \mathrm{Mpa} \sqrt{\mathrm{m}}$ for a thermal neutron fluence of $2.5 \times 10^{26} \mathrm{~m}^{-2}$, falling to about $17 \mathrm{Mpa} \sqrt{\mathrm{m}}$ at $7.5 \times 10^{26} \mathrm{~m}^{-2}$.

\subsection{A SPECTRAL EFFECT?}

The tensile properties data base in Fig. 4.4 represents, primarily, irradiations made in a narrow range of hard spectra in light water reactors. The one exception is data from components irradiated in the softer spectra of the heavy water HFBR. ${ }^{20.21}$ These data show considerably more strengthening per unit of fluence. They also are claimed to give low fracture toughness values (see Sect. 4.2). Transmission electron microscopy (TEM) examination reveals a much finer distribution of the precipitates of radiation-induced silicon, consistent with the higher strengths. The finer microstructure is tentatively attributed to the softened neutron spectrum of the HFBR. It is postulated ${ }^{21,30}$ that, whereas the thermal neutrons produce the silicon, it is the fast neutrons that determine its spatial distribution by controlling the degrees of cascade dissolution of precipitates and vacancy supersaturation. In that case, if the fast neutron flux is low with respect to the thermal neutron flux, there will be less coarsening of the silicon precipitate and, hence, more strengthening per unit of silicon or per unit of thermal neutron fluence. On this basis, a spectrum like that for some of the HFBR data with a $\phi_{\mathrm{LL}} / \phi_{\mathrm{f}}$ ratio of 20 or so will cause more hardening per unit of thermal neutron fluence than will the light water HFIR spectrum, where the ratio is -2 . A ratio of 0.5 will cause less strengthening.

This interpretation is speculative. It is marred by uncertainties in irradiation temperatures. Nevertheless, it is not an isolated observation. A sensitivity to $\phi_{\mathrm{th}} / \phi_{\mathrm{f}}$ ratio has been reported for the 
ORNL-DWG 95M-6743

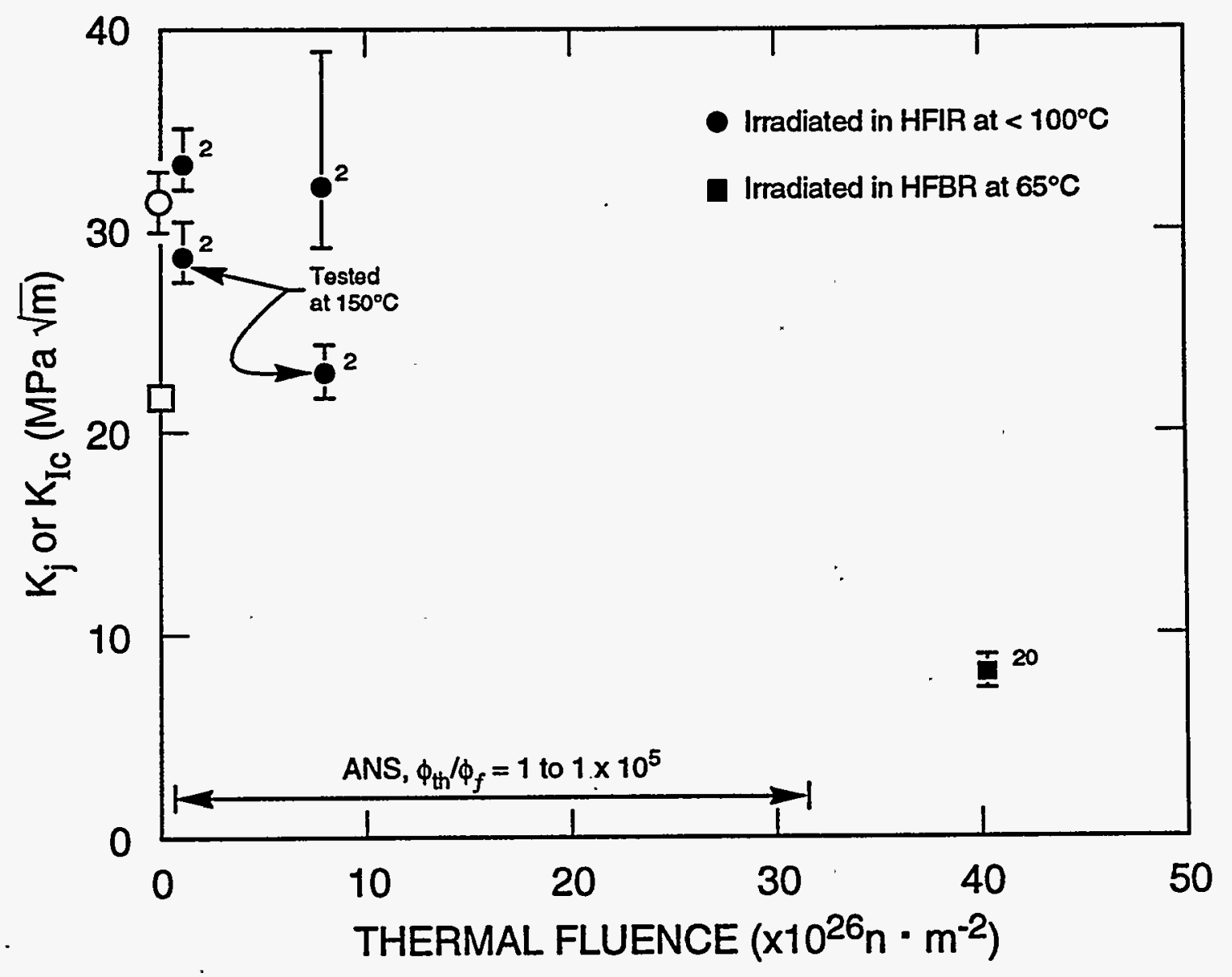

Fig. 4.5. Fracture toughness of 6061-T6 and 6061-T651 after neutron irradiation at temperatures $<100^{\circ} \mathrm{C}$. 
This interpretation is speculative. It is marred by uncertainties in irradiation temperatures. Nevertheless, it is not an isolated observation. A sensitivity to $\phi_{\mathrm{th}} / \phi_{\mathrm{f}}$ ratio has been reported for the tensile properties of specimens of 5154 aluminum alloy $(\mathrm{Al}-3.5 \% \mathrm{Mg})$ cut from the retired core box of the high flux reactor at Petten, ${ }^{29}$ where $\phi_{\mathrm{th}} / \phi_{\mathrm{f}}$ values spanned only a very narrow range of 1 to 4.8 and temperature was apparently not a variable. Also, unpublished but widely known data measured on the AG3-NET alloy (AL-3\% Mg) beam tubes in the Reacteur Haut Flux (RHF) at Grenoble, for which the $\phi_{\mathrm{uh}} / \phi_{\mathrm{f}}$ ratios were in the range of 80-500, show that hardnesses are much higher than for similar material irradiated to similar thermal fluences in the HFIR at $\phi_{\mathrm{un}} / \phi_{\mathrm{f}}=2$. This loosely knit but consistent body of evidence cannot be ignored. Until more information and a more positive explanation are available, the prudent course is to accept the possibility that spectral effects will occur in ANS components where $\phi_{\mathrm{hh}} / \phi_{\mathrm{f}}$ ratios will range as high as $1 \times 10^{5}$. Presently, the data in Figs. 4.4 and 4.5, on which the following assessment of the ANS components is based, cover only the narrow $\phi_{\mathrm{th}} / \phi_{\mathrm{f}}$ range of $0.5-21$. Allowances should be made for the much higher ratios in the ANS, but there are inadequate data to guide the allowances, and quantitative predictions cannot be attempted with confidence.

\section{Recommendation \#2: Experiments should be made at measured temperatures to verify and quantify effects of the ratio of thermal to fast flux on tensile and fracture toughness properties of neutron- irradiated 6061-T6 alloy.}

\subsection{INTERGRANULAR FRACTURE}

The tensile data in Fig. 4.4 are for irradiation and test temperatures $<100^{\circ} \mathrm{C}$. The fracture mode is usually transgranular ductile tearing. However, at the higher doses there are rims of intergranular fracture at those surfaces that were in contact with water during irradiation. Such intergranular fracture may be associated with absorption into the grain boundaries of radiolysis products from the water. Longer exposure times or higher operating temperatures would be expected to increase the depth of penetration of radiolysis products, resulting in reduced ductility.

Intergranular fracture is a mode of failure that occurs by separation of the boundaries between grains in a solid, usually at low strains. It is attributed to segregation of impurity atoms at the boundaries that reduces cohesion across the boundaries and to deformation conditions that tend to concentrate plastic strain at the grain boundaries, as in low-stress creep. Intergranular failure does not require any associated hardening, and regular tests for ductility may not reveal any propensity to intergranular weakness. Often it is environmentally related, as in the well-known phenomenon of intergranular stress corrosion cracking and in the above instances of radiolysis effects. Or it may be caused by internal impurities, as with helium embrittlement. It can happen unexpectedly and is blamed for the two most serious cases of in-reactor failures of aluminum components. These are the splitting of the tubular, 8001 alloy (Al-1\% Ni) HFIR target elements ${ }^{31}$ and the craze cracking of the AG3-NET alloy (AL-3\% Mg) beam tubes in the RHF at Grenoble. The former was traced to helium embrittlement because of high local concentrations of helium generated at stringers of nickel-rich inclusions in the extruded tubing. ${ }^{32}$ It was eliminated by reducing the volume of target material and thereby removing the tensile hoop stress on the tubing. The RHF intergranular cracking, which necessitated replacement of the beam tubes, remains unexplained but is tentatively blamed on stresscorrosion cracking. Both of these incidents were surprises.

There are intermittent signs that intergranular cracking can intervene in irradiated 6061-T6 alloy. It is found that testing of irradiated specimens at temperatures above $150^{\circ} \mathrm{C}$ reveals very low ductility, associated in some cases with the onset of intergranular failure. ${ }^{18}$ Furthermore, postirradiation creep tests at low stresses at $100^{\circ} \mathrm{C}$ and $150^{\circ} \mathrm{C}$ tend to be terminated abruptly by intergranular failure at low 
intergranular facets. These signs reinforce the earlier recommendations that temperatures not exceed $150^{\circ} \mathrm{C}$ and stresses be minimized. They also lead to the following recommendation.

Recommendation \#3: Experiments should be conducted to determine the temperature-stress-fluence limits in water for the occurrence of intergranular fracture in neutron-irradiated 6061-T6 aluminum.

\subsection{RADIATION CREEP}

In stressed specimens undergoing irradiation, the excess point defects produced by the irradiation can induce radiation creep mechanisms that supplement thermal creep and increase the overall rates of creep. Radiation creep will relieve peak stresses but will cause dimensional changes in components. Because the supersaturations of point defects increase with decreasing temperature, the relative contribution of radiation creep to total creep should also increase with reduced temperature. Radiation creep can extend the range of creep below temperatures where thermal creep is usually insignificant. There are only two reports of in-reactor creep experiments on aluminum. Both are on high-purity aluminum. One, ${ }^{34}$ at a displacement level of only $10^{-5} \mathrm{dpa}$, found no radiation creep. In the other, ${ }^{35}$ at $10^{-4} \mathrm{dpa}$, the creep rate was increased by a factor of 10 or more for irradiation temperatures below $150^{\circ} \mathrm{C}$. It might be argued that since $6061-\mathrm{T} 6$ alloy is more resistant to thermal creep than is pure aluminum and has a high concentration of precipitates that will absorb and recombine point defects, it might be less sensitive to radiation creep.

Radiation creep is considered a serious issue requiring immediate resolution for some components of the ANS. The primary concern is the CPBT, which is the principal pressure boundary in the ANS. Creep will cause it to barrel outwards. To address this concern, the ANS Project has initiated some radiation creep experiments on 6061-T6 alloy. These experiments consist of making measurements of changes in diameter of internally pressurized tubes of 6061-T651 aluminum after irradiation in the HFIR flux trap at a temperature of about $65^{\circ} \mathrm{C}$. The tubes are pressurized with helium to produce hoop stresses in the tube walls of 20,60 , and $100 \mathrm{Mpa}$. These stresses and the neutron fluxes in the trap are close to those expected for the CPBT. The irradiation temperature is on the low side, a condition that should favor radiation creep by ensuring greater supersaturations of radiation-produced point defects. . Data from the first tests at fluences up to $1.5 \times 10^{25} \mathrm{~m}^{-2}$ thermal and $5.2 \times 10^{24} \mathrm{~m}^{-2}$ fast and $0.8 \mathrm{dpa}$ reveal no creep. These results are very encouraging, but are by no means conclusive. They are lowdose data and at best indicate that creep in this alloy is not significant in the point defect transient period at the onset of irradiation before steady state conditions are established. Longer-term tests are underway.

\subsection{FATIGUE}

There is no information on effects of irradiation on fatigue of 6061-T6 aluminum. Failures of some 6061-T6 shim safety-rod bearing mounts in the HFIR shortly after the reactor was commissioned were traced to fatigue and were rectified by redesigning the mounts. ${ }^{36}$ No influence of the radiation environment was discerned. In 5154 aluminum alloy irradiated to a thermal neutron fluence of $7.5 \times 10^{26} \mathrm{~m}^{-2}$, fatigue crack growth rates were increased by a factor of $2 .{ }^{29}$ In other irradiated metals where fatigue data exist, mostly stainless steels, the general trends are that radiation extends fatigue life under high frequency conditions and reduces fatigue life under low-cycle, strain-controlled conditions. The changes are modest, factors of approximately 2 to 5 . Thus, it seems that radiationenhanced fatigue is not a serious issue. The best safeguards against fatigue in reactor components are 
designing the components for fatigue resistance, decoupling sources of vibration, and minimizing cyclic stresses.

\subsection{LOW TEMPERATURES}

Aluminum components in the two cold sources in the ANS will operate in liquid deuterium at $-253^{\circ} \mathrm{C}$. At such temperatures atomic diffusion processes will virtually cease. Loss of point defects by diffusional recombination will be inhibited, as will the formation of precipitates of transmutationproduced silicon. The point defects and the silicon atoms will be frozen in, causing very high supersaturations of defects that will induce considerable solid solution-type hardening. Additionally, a much larger fraction of point defect clusters created by cascade collapse will avoid attrition by mobile defects than would do so at higher temperatures. Consequently, it is expected that the degree of radiation hardening per unit of dpa or of fluence will be considerably higher than for ambient temperature irradiations. This assumption is confirmed by limited cryogenic irradiation data on tensile properties of aluminum alloys summarized in Ref. 10. Specifically, for 6061-T651 alloy irradiated in a fairly hard spectrum at $-196^{\circ} \mathrm{C}$ to a fast neutron fluence of $2 \times 10^{23} \mathrm{~m}^{-2}(\approx 0.03 \mathrm{dpa})$ and tested at $-196^{\circ} \mathrm{C}$, there was a $41 \%$ increase in yield strength, a $22 \%$ gain in ultimate strength, a loss of $54 \%$ in total elongation, and a loss of $95 \%$ in uniform elongation. ${ }^{37}$ Likewise, pure aluminum irradiated under similar conditions displayed a 50\% increase in tensile strength and a total loss in uniform elongation. ${ }^{38}$ Irradiation to these low fluences at ambient reactor temperature would cause only barely perceptible changes in properties. Actually, much of the changes in properties in the 6061 alloy occurred at a fast neutron fluence of only $4 \times 10^{22} \mathrm{~m}^{-2}$, or $-6 \times 10^{-3} \mathrm{dpa}$. The ANS cold source vessels will reach a displacement dose of $6 \times 10^{-3}$ dpa just five days into the reactor's first fuel cycle.

The spectrum at the cold source vessels is very soft, $\phi_{\mathrm{t}} / \phi_{\mathrm{f}}=8 \times 10^{3}$, and from Fig. 4.4 it can be seen that $-95 \%$ of the displacements will be created by low-energy recoil events associated with the thermal neutrons. Accordingly, there will be fewer cascade clusters and perhaps less hardening. On the other hand, relatively large quantities of silicon will be generated and retained in supersaturated solid solution with an expected high hardening coefficient. Therefore, the designers of the ANS cold sources have assumed, prudently, that neutron exposure for a single 17-d fuel cycle will severely embrittle the cold source vessels.

Some relief is available. A characteristic of low-temperature radiation damage is that much of it anneals out when the temperature is raised to a level where point defects become mobile. For 6061 aluminum, it was found that tests made at room temperature after irradiation at $-196^{\circ} \mathrm{C}$ showed no detectable hardening. ${ }^{37}$ Such restoration of properties is consistent with the fact that irradiation to these fluences at ambient temperature, where such annealing is concurrent, will not cause significant changes in tensile properties. This ability to recover from low-temperature radiation damage in an aluminum cold source by bringing it up to room temperature is the reason that cold sources are usually allowed to heat up to ambient temperature periodically. A periodic annealing schedule is planned for the ANS cold sources to coincide with fuel changes. Of course, the annealed sources will rapidly reharden during the next fuel cycle and must be regarded as brittle, but, at least during fuel changes, when the danger of inadvertent handling damage to the sources is greatest, they will be more able to withstand . shocks.

Although room-temperature annealing of this type will certainly erase mobile point defects and seems to be satisfactory for existing cold neutron sources, there is some question of its efficacy for mitigating the hardening caused by large quantities of transmutation-produced silicon. Supersaturated solid solutions of silicon in aluminum will age harden at room temperature. The generation rate of silicon in the ANS cold sources will greatly exceed that in any existing cold neutron sources, and it is not clear whether a room-temperature anneal will relieve or aggravate the hardening from the silicon. 
For acceptable relief from silicon-associated hardening, it may be necessary to go to higher temperature, but not beyond $160^{\circ} \mathrm{C}$, where overaging of the 6061 alloy will occur. To prepare for this contingency, the ANS cold source designers are exploring an innovative use of nuclear afterheat to raise the temperature of the cold sources above room temperature.

\subsection{SWELLING}

Swelling is an increase in volume caused by development of voids, bubbles, and low-density phases. It can be measured from the difference in density of unirradiated $\left(\rho_{0}\right)$ and irradiated $\left(\rho_{i}\right)$ aluminum. Measurements of swelling in various aluminum alloys irradiated at $65^{\circ} \mathrm{C}$ in the HFIR are presented in Fig. 4.6. By convention, swelling is plotted against fast neutron fluence because in most materials swelling results primarily from voids and because voids are developed from accumulations of vacancies, most of which are generated by fast neutrons. In aluminum, the silicon precipitates developed during irradiation are less dense than the aluminum matrix, and they cause swelling, too. The density of 6061 alloy is $2701.2 \mathrm{~kg} \mathrm{~m}^{-3}$. That of silicon is $2329.3 \mathrm{~kg} \mathrm{~m}^{-3}$, and $1 \mathrm{wt} \% \mathrm{Si}$ in the form of precipitate will cause $0.16 \%$ swelling. The silicon portion of the swelling is dependent on the thermal neutron fluence. For the data in Fig. 4.6, the $\phi_{\mathrm{th}} / \phi_{\mathrm{f}}$ ratio is -2 . The silicon contribution to swelling is indicated by the dashed line marked ${ }^{28} \mathrm{Si}$. The difference in swelling between the dashed line and the solid lines is the void swelling. (In the $5052-0$ alloy, $\mathrm{Al}-2.5 \% \mathrm{Mg}$, the neutron-generated silicon increases the density of the alloy because it combines with $\mathrm{Mg}$ to form $\mathrm{Mg}_{2} \mathrm{Si}$; removal of the $\mathrm{Mg}$ from solid solution raises the density of the matrix.)

Study of Fig. 4.6 reveals that, although swelling in pure aluminum is due principally to voids and is quite high, the 6061-T6 alloy is much more resistant to void formation and displays only about one hundredth the overall swelling, most of it attributable to the silicon precipitates. Void swelling is not a factor until a fast neutron fluence of $3 \times 10^{26} \mathrm{~m}^{-2}$ is reached. Table 3.1 shows that the maximum fast neutron fluence received by any ANS component is $5-6 \times 10^{26} \mathrm{~m}^{-2}$ (for the control rod followers and the in-core MT tubes). Therefore, swelling in the ANS components will be dominated by the silicon precipitate.

Swelling from silicon precipitates should not be strongly sensitive to irradiation temperature. Swelling from voids is sensitive to irradiation temperature through its effects on vacancy mobility and the degree of vacancy supersaturation. Experiments on pure aluminum have shown that void swelling diminishes at irradiation temperatures above $65^{\circ} \mathrm{C}$ and disappears at about $150^{\circ} \mathrm{C}$. Hence, the higher irradiation temperatures in the ANS should reduce void swelling below that for the fast fluences depicted in Fig. 4.6. Swelling in the in-core components, where the spectrum is similar to that for Fig. 4.6, should not exceed $-0.5 \%$. Elsewhere, swelling will be determined by the silicon precipitate and can be estimated from the silicon concentrations in Table 3.1. The largest accumulated silicon levels are $6.4 \%$ in HT- 4 and the beam tube thimbles and $6.0 \%$ in the cold source thimbles. In these components, swelling is predicted to be on the order of $1 \%$; at least it will be if the silicon precipitates are pure, crystalline silicon. Sometimes they are not crystalline. Amorphous particles of silicon have been found, especially in materials irradiated in a thermalized neutron spectrum. Their contribution to swelling has not been measured.

\subsection{RADIATION SOFTENING}

Generally, metals undergo hardening during irradiation. It is conceivable, however, that metals that have been prehardened by cold work or by a precipitation treatment might become softened during irradiation at temperatures below the normal temperature for thermal recovery as a result of radiationenhanced diffusion processes or cascade dissolution of precipitates. Early measurements of the effects 


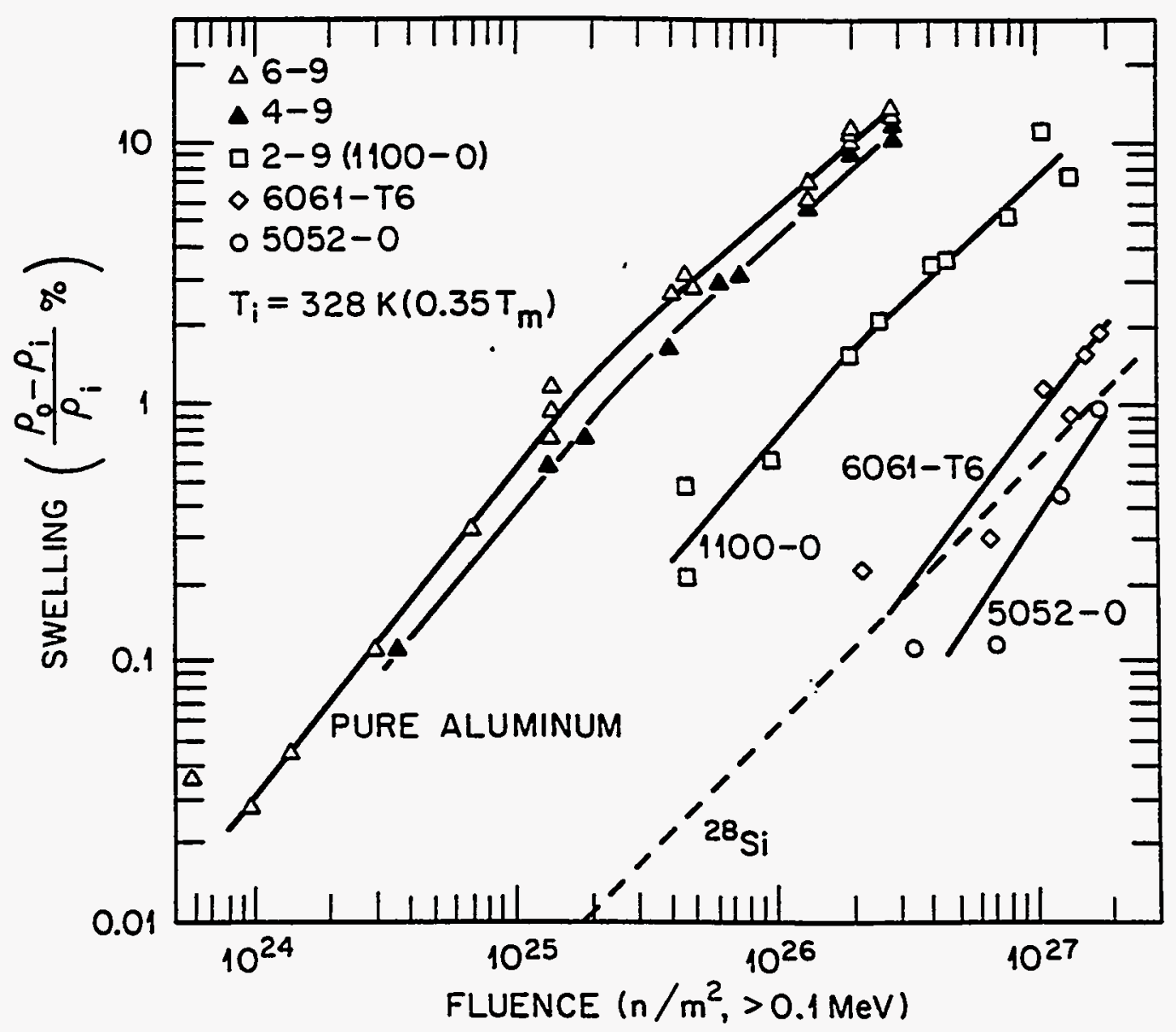

Fig. 4.6. Swelling in neutron-irradiated aluminum alloys. 
of irradiation temperature on the tensile properties of $6061-\mathrm{T} 6$ aluminum ${ }^{23}$ showed that full softening under irradiation occurred only at temperatures of $250^{\circ} \mathrm{C}$ or higher, coincident with those for thermal softening and implying that radiation softening was not occurring. In agreement, the tensile data from the numerous sources in Fig. 4.4 for $6061-\mathrm{T} 6$ and -T651 alloys neutron irradiated at temperatures below $100^{\circ} \mathrm{C}$ indicate no softening. Nevertheless, there are two disturbing reports of radiation-induced softening in 6061-T6 type alloys. The first ${ }^{39}$ was for $6061-\mathrm{T} 6$ material irradiated with $600-800 \mathrm{MeV}$ protons to a displacement dose of $0.2 \mathrm{dpa}$. The other ${ }^{40}$ was for a quenched-and-tempered alloy $(0.78 \mathrm{Mg}, 0.98 \mathrm{Si})$ irradiated to fast neutron fluences of $8.7 \times 10^{21} \mathrm{~m}^{-2}$ and $2.5 \times 10^{22} \mathrm{~m}^{-2}\left(-1.5 \times 10^{3}\right.$ and $4 \times 10^{3} \mathrm{dpa}$, respectively). In both cases, yield strengths and ultimate strengths were reduced to the levels for annealed alloy, and ductility was increased. In the proton-bombarded alloy, the $\mathrm{Mg}_{2} \mathrm{Si}$ precipitate disappeared. No microscopy was done on the neutron-irradiated alloy.

Until the publication of the second report, the proton bombardment softening of 6061-T6 alloy had been regarded with skepticism because of the notoriously erratic temperature control in many early ion bombardments. The second report generated considerable concern at ORNL and prompted extensive experiments to verify the softening phenomenon. Tensile specimens of 6061-T6 and -T651 and four other precipitation-hardened aluminum alloys were exposed in the HFIR target region to fluences that blanketed the reported softening ranges. No softening was found. Because the flux in the HFIR trap is much higher than that for the reported softening, specimens were placed in the Ford Reactor at the University of Michigan to duplicate the appropriate conditions of spectrum, flux, and time for the purported radiation softening. Again, no softening was found. The proton bombardment conditions that caused softening could not be attained at ORNL. A simulation was performed with $2.3 \mathrm{MeV}$ protons. Still, no softening was found. One significant difference between these experiments and those for the claimed softening is temperature control. The experiments that gave softening were done in sealed cans with no measurements of the actual temperatures of the specimens. The subsequent experiments, which showed no softening, were made with the specimens in direct contact with flowing cold water for the neutron irradiations and in a fully temperature-controlled and monitored system for the proton bombardments. It was concluded that the reported cases of radiation softening in 6061-T6 alloy were probably instances of largely thermal softening caused by inadequate attention to control of radiation heating.

There is a telling postscript to these radiation softening claims. The author of this report communicated the ORNL experimental details and conclusions to the authors of the claims. Some time later he was informed by one of the authors of the proton irradiations that they had improved the cooling system on their machine, repeated their irradiations on the 6061-T6 alloy, and found no softening. The author of the neutron irradiation softening claim has very recently published the results of follow-up work ${ }^{41}$ in which steps were taken to ensure good heat transfer to the cooling water. ${ }^{41}$ The specimens were irradiated to a fast neutron fluence of $3.7 \times 10^{22} \mathrm{~m}^{-2}$, and no softening occurred. No public retractions have been made of either of the original softening claims. The softening data are omitted from Fig. 4.4.

This review of radiation softening, while seemingly favorable for precipitation-hardened 6000-type alloys, is not the whole story. There are two instances ${ }^{42,43}$ in which cold-worked, commercial-purity aluminum reactor components in service at $40-50^{\circ} \mathrm{C}$ displayed softening at low fluences and radiation hardening at higher fluences, and TEM examinations confirmed that recovery of the cold-worked dislocation microstructure had occurred. There are no grounds to doubt the temperatures, so these two instances must be viewed as genuine cases of radiation-accelerated softening. The aforementioned ORNL experiments to detect the supposed radiation softening in the precipitation hardened alloys included specimens of cold-worked, commercial-purity aluminum. The cold-worked aluminum did not soften. This disagreement with the findings of Refs. 42 and 43 is interpreted as an indication that radiation-assisted recovery of dislocation structure is slow at $50^{\circ} \mathrm{C}$ and requires long exposures or 
the claimed softening in the precipitation-hardened 6000-type alloys is moot. Certainly, it does not hold for the data in Fig. 4.4, which contain measurements made on materials irradiated for periods up to 20 years. Therefore, at irradiation temperatures below $100^{\circ} \mathrm{C}$, radiation softening should not be a problem for precipitation-hardened 6061-T6 and -T651 alloy.

\subsection{EFFECTS OF GAMMA RAYS}

Gamma rays can indirectly produce atomic displacements in metals by Compton scattering and electron-positron pair production in which the energized electrons cause the displacements. The displacement cross section in medium $\mathrm{Z}$ metals for gamma rays with energies greater than $-2 \mathrm{MeV}$ is on the order of $1 b, 4$ which is about $1 / 1000$ that for fast neutrons with energies greater than $0.1 \mathrm{MeV}$. Therefore, displacements from gamma rays are usually relatively small and are ignored. However, when the ratio of gamma flux $(E>2 \mathrm{MeV})$ to fast neutron flux $(E>0.1 \mathrm{MeV})$ exceeds $\sim 1000$, the fraction of atomic displacements contributed by gamma rays will be substantial. Table 3.1 shows that the reflector vessel has a gamma to fast flux ratio of $2 \times 10^{3}$. Will this high ratio affect radiation damage in the vessel? Probably not. The reason for this seeming retreat is that the above argument holds only when most of the neutron-induced displacements result from fast neutrons. At the ANS vessel, almost all of the atomic displacements are produced by thermal neutrons (see Table 3.1). Because the thermal neutron flux at the vessel is ten times larger than the high-energy gamma flux and the displacement cross sections for thermal neutrons and gamma rays are similar, the gamma-induced displacements will be relatively negligible.

\subsection{THERMAL CONDUCTIVITY}

One of the reasons for selecting 6061 alloy for the reactor internal components is its high thermal conductivity. The nuclear heat generated in the components must be transferred readily to the cooling water. The thermal conductivity of aluminum is reduced by the presence of foreign atoms in the lattice. Hence, unirradiated 6061 alloy has about $90 \%$ of the thermal conductivity of pure aluminum. There are no measurements of thermal conductivity in irradiated 6061 alloy, but the effects of irradiation are not expected to be large. The development of surface oxide films will likely be much more detrimental to heat transfer rates than will changes in bulk thermal conductivity. This effect of surface oxide films has been extensively studied in the ANS Project to ensure that the films do not cause unacceptably high temperatures in the reactor components and fuel plates. 
- " 


\section{ASSESSMENT OF ANS REACTOR COMPONENTS}

From this background and with the caveats regarding the unclear effects of irradiation temperature, intergranular fracture, and thermalized spectrum in aluminum, the state of radiation damage induced in individual 6061-T6 components by their specific radiation environments is now assessed. In some cases, the components will be declared "embrittled," for lack of a better term to describe a condition in which the mechanical properties are expected to be severely impaired but some level of ductility is likely to be retained. For present purposes, this condition is arbitrarily defined as having a combination of thermal neutron fluence greater than $8 \times 10^{26} \mathrm{~m}^{-2}$ and either a $\phi_{\mathrm{u}} / \phi_{\mathrm{f}}$ ratio of $>20$ or an irradiation temperature of $150^{\circ} \mathrm{C}$ or both. Under those criteria, a component would have less than $5 \%$ uniform elongation in tension, according to Fig. 4.4, with the prospect of even lower ductility because of the high temperature, and it may fall in the contentious region of low fracture toughness in Fig. 4.5. A component designated embrittled under these terms is not necessarily hazardous. Aluminum very rarely breaks as glass does in a truly brittle manner. More likely it will deform before suffering gross failure. Those components labeled embrittled and for which failure will not jeopardize the safe operation of the reactor, may still be considered fit for service. The limits to their service lives are not established by their metallurgical condition alone. Replacement costs, reactor outage penalties, and other factors are considered. This assessment stops short of proposing useful service lives, although it does include suggestions for determining a better appraisal of metallurgical condition of some components for which the present information is inadequate.

This assessment begins with components in the hard spectrum region of the core, then moves radially outward into the more thermalized regions in the heavy water reflector. Each component is introduced with a synopsis of its operating conditions, where its goal life $(\mathrm{L})$ is given in calendar years; $\phi t_{c h}$ is the lifetime thermal neutron fluence $(E<0.625 \mathrm{eV})$ in units of neutrons per square meter; $\phi_{\mathrm{u}} / \phi_{\mathrm{f}}$ is the ratio of thermal neutron flux to fast $(\mathrm{E}>0.1 \mathrm{MeV})$ neutron flux; $\sigma$ is the peak stress; and $T$ is the peak operating temperature.

\subsection{CONTROL ROD FOLLOWERS AND IN-CORE MATERIALS TESTING TUBES}

$$
\mathrm{L}=2 \text { years, } \phi \mathrm{t}_{\mathrm{ch}}=-1 \times 10^{27}, \phi_{\mathrm{Lb}} / \phi_{\mathrm{f}}=1-2, \sigma=90 \mathrm{Mpa}, \mathrm{T}=?
$$

These components are located within the hollow, cylindrical fuel elements. Their operating temperatures have not been specified. It might be assumed that, because these components are in the direct path of the inlet coolant water, their temperatures will remain below $100^{\circ} \mathrm{C}$. But they also experience the largest nuclear heating rates, as high as $40 \mathrm{~W} / \mathrm{g}$. Spectrum effects are not expected for these components. Swelling will be small $(<0.5 \%)$. These components will harden and lose much of their ductility as per the appropriate fluence in Fig. 4.4, but no serious problems are foreseen for them, provided their temperatures are maintained below about $125^{\circ} \mathrm{C}$.

\subsection{CORE PRESSURE BOUNDARY TUBE}

$$
\mathrm{L}=0.5 \text { years, } \phi t_{t h}=5 \times 10^{26}, \phi_{\mathrm{th}} / \phi_{\mathrm{f}}=3, \sigma=92-96 \mathrm{Mpa}, \mathrm{T}=105^{\circ} \mathrm{C}
$$

The CPBT is the principal pressure boundary in the reactor. It must not break. The major concern is the possibility of a sudden failure. Hence, the CPBT is intended to be of double-wall construction or at least with a guard tube. The exposure conditions given above are for the horizontal centerline, where the flux and hoop stress will be maximum. Towards the ends of the tube, the flux, temperature, 
and stress levels will decline, and the $\phi_{\mathrm{th}} / \phi_{\mathrm{f}}$ ratio will increase considerably. At the centerline, the short exposure time, the modest thermal fluence, the low $\phi_{\mathrm{L}} / \phi_{\mathrm{f}}$ ratio, and the moderate temperature conspire to alleviate embrittlement concerns to a large degree. Alexander's recent fracture toughness data ${ }^{26,28}$ show little or no change in toughness at thermal neutron fluences up to $8 \times 10^{26} \mathrm{~m}^{-2}$. Also, the perceived threat of distortion by radiation creep is diminishing in view of ongoing creep tests, which are not showing significant creep. Swelling should be less than $0.2 \%$. All in all, then, the prospects for successful deployment of the CPBT in the above service conditions look good. For reasons described earlier and in Sect. 6, welds are avoided in the highly stressed regions of the tube.

\subsection{HYDRAULIC TUBES HT-2 AND -4 AND SH-1 AND -2}

$$
\mathrm{L}=2 \text { years, } \phi \mathrm{t}_{\mathrm{hh}}=3 \times 10^{27}, \phi_{\mathrm{Lh}} / \phi_{\mathrm{f}}=15-50, \sigma=20-44 \mathrm{Mpa}, \mathrm{T}=120-150^{\circ} \mathrm{C}
$$

These components will receive high thermal neutron fluences at moderately high $\phi_{\mathrm{uh}} / \phi_{\mathrm{f}}$ ratios. These conditions fall in the disputed low-toughness region of Fig. 4.5. Also, the temperature is in the regime where very low ductility is encountered in tensile tests. These tubes will be embrittled. Their stresses are low and presumably are compressive, conditions that are somewhat compensatory. Nevertheless, the uncertainties in effects of temperature and spectrum make prediction of properties difficult. Implementation of Recommendations 2 and 3 would provide information for firmer predictions. Additionally, site-specific properties data will be obtained after reactor startup by loading one or more of the tubes with surveillance specimens and withdrawing and testing the specimens at intervals to monitor progressively the nature and extent of the radiation damage.

\subsection{BEAM TUBE THIMBLES}

$$
\mathrm{L}=2 \text { years, } \phi \mathrm{t}_{\mathrm{th}}=3 \times 10^{27}, \phi_{\mathrm{th}} / \phi_{\mathrm{f}}=130, \sigma=44 \mathrm{Mpa}, \mathrm{T}=125^{\circ} \mathrm{C}
$$

The tips of these thimbles are located in the peak thermal flux region just outside the CPBT. In their planned 2-year lifetime, they will receive a high thermal neutron dose at high $\phi_{\mathrm{un}} / \phi_{\mathrm{f}}$ ratio and moderately high temperature. Approximately $6.4 \%$ Si will be generated, resulting in $-1 \%$ swelling. The thimbles will be embrittled. Special care will be taken to protect them from shock and impact. These thimbles will be under a compressive load from the $\mathrm{D}_{2} \mathrm{O}$ reflector, but they have elliptical cross sections. Consequently, there will be a component of tensile stress on.them that might encourage corrosion problems. A design change to circular section tubes that will eliminate the tensile stress is planned.

The unexpected failures of the beam tubes of the RHF at Grenoble have focused attention on corrosion of aluminum beam tubes under irradiation. The RHF tubes cracked and spalled when they reached thermal neutron fluences of $6-8 \times 10^{26} \mathrm{~m}^{-2}$ in $\mathrm{D}_{2} \mathrm{O}$ and a high $\phi_{\mathrm{th}} / \phi_{\mathrm{f}}$ spectrum. Cracking was preceded by the appearance of small, white florets of corrosion product on the outer surfaces of the tubes. The alloy is AG3-NET, a high-purity aluminum with $3 \% \mathrm{Mg}$. It was developed as a lowactivation alloy and does not contain the small amounts of copper and chromium that are added to other aluminum alloys to control grain size and to impart improved corrosion resistance. Welds made in the tubes with $\mathbf{5 0 5 2}$ aluminum filler wire, which does contain the additives, did not crack. This discrepancy implies that the cracking is material related, a deduction supported by the fact that the 6061-T6 beam tubes of the HFIR in $\mathrm{H}_{2} \mathrm{O}$ and the HFBR in $\mathrm{D}_{2} \mathrm{O}$ have experienced higher fluences without corrosion and cracking. These considerations portend well for possible immunity of the ANS beam tubes to this type of cracking. Nonetheless, such immunity is speculative. For greater certainty a regular inspection schedule should be implemented to search for telltale signs of corrosion and 
spallation on the tubes. The experiments suggested in Recommendation \#3 (determination of temperature-stress-fluence limits for occurrence of intergranular fracture in water) would provide further guidance for optimum utilization of the beam tube thimbles.

\subsection{COLD SOURCE THIMBLES}

$$
\mathrm{L}=2 \text { years, } \phi \mathrm{t}_{\mathrm{h}}=3 \times 10^{27}, \phi_{\mathrm{th}} / \phi_{\mathrm{f}}=330, \sigma=42 \mathrm{Mpa}, \mathrm{T}=125^{\circ} \mathrm{C}
$$

The exposure conditions for the cold source thimbles are similar to those for the beam tube thimbles. They will be embrittled. The comments made for the beam tube thimbles hold for the cold source thimbles, too.

\subsection{COLD SOURCE VESSELS}

$$
\mathrm{L}=2 \text { years, } \phi \mathrm{t}_{\mathrm{hh}}=2 \times 10^{27}, \phi_{\mathrm{th}} / \phi_{\mathrm{f}}=8 \times 10^{3}, \sigma=50 \mathrm{Mpa}, \mathrm{T}=-253^{\circ} \mathrm{C}
$$

The special case of irradiation effects at cryogenic temperatures was outlined in Sect. 4.7. The cold source vessels will become severely embrittled after only a few days' exposure. There is no practical and economical way to avoid this effect, so the embrittlement must be accommodated. The most feasible ways are to set up strict procedures to minimize the danger of handling damage and to incorporate a recovery anneal at the end of each fuel cycle, as described in Sect. 4.7. The anneal affords only temporary restitution of properties, but it limits accumulation of radiation damage to a maximum exposure of one fuel cycle, assuming that the silicon is rendered innocuous by the anneal, and it periodically relieves internal stresses developed in the vessels by the stored point defects. Frequent and systematic annealing of the vessels is an essential item of circumspect management of the cold sources.

Annealing at room temperature should be sufficient to remove vacancy and interstitial point defects. Erasing or diminishing the embrittling effects of the transmutation-produced silicon may require higher temperatures. The appropriate annealing temperature will need to be determined by experiment or from the French experience with their cold sources. Care must be taken to avoid overtempering the 6061 alloy. If it is imperative to maintain the full strength of a T6 condition in the vessels after annealing, the annealing temperature will be restricted to a maximum of $160^{\circ} \mathrm{C}$. Lesser strength requirements will allow higher annealing temperatures.

\subsection{HOT SOURCE THIMBLE}

$$
\mathrm{L}=2 \text { years, } \phi \mathrm{t}_{\mathrm{Lh}}=2 \times 10^{27}, \phi_{\mathrm{Lh}} / \phi_{\mathrm{f}}=8 \times 10^{3}, \sigma=50 \mathrm{Mpa}, \mathrm{T}=125^{\circ} \mathrm{C}
$$

The hot source thimble and the hydraulic tubes HT-1 and HT-3 (see Sect. 5.8) share similar neutron environments, the major characteristic of which is the exceptionally high degree of thermalization. Maintenance of the integrity of the hot source thimble is paramount. Its thermal neutron fluence of $2 \times 10^{27} \mathrm{~m}^{-2}$ should cause $-0.6 \%$ swelling. The tensile strength and fracture toughness are not predictable from Figs. 4.4 and 4.5 because the figures reveal nothing about the fluence response of 6061 alloy in the very soft spectrum seen by the hot source thimble. If the explanation put forward for the substantial increase in strength observed in a spectrum with $\phi_{\mathrm{th}} / \phi_{\mathrm{f}}=20$ is correct, then the spectrum at the hot source thimble should cause considerably greater strengthening and associated loss in toughness than indicated in Figs. 4.4 and 4.5. Thus, the hot source thimble must be considered to be embrittled. Two actions can be taken to reduce the severity and uncertainty of the 
embrittlement. One is to shorten the planned lifetime of the first hot source thimble to 0.5 years, immediately test the retired thimble, and adjust the service life of its successors according to the test results. The other is either to carry out Recommendation \#2 (determine effects of spectrum) before the ANS is built or to plan on placing surveillance specimens in HT-1 or HT-3 to monitor the effects and progress of radiation damage at a $\phi_{t h} / \phi_{f}$ ratio pertinent to the hot source thimble. It will be difficult to find an existing radiation source with fluxes high enough to allow Recommendation $\# 2$ to be performed in a reasonable period of time.

\subsection{HYDRAULIC TUBES HT-1 and -3}

$$
\mathrm{L}=2 \text { years, } \phi \mathrm{t}_{\mathrm{hh}}=9 \times 10^{26}, \phi_{\mathrm{th}} / \phi_{\mathrm{f}}=8 \times 10^{4}, \sigma=?, \mathrm{~T}=100^{\circ} \mathrm{C}
$$

See comments above for the hot source thimble.

\subsection{VT-1 AND PT-1 TUBES}

$$
\mathrm{L}=2 \text { years, } \phi t_{\mathrm{hh}}=2-9 \times 10^{26}, \phi_{\mathrm{th}} / \phi_{\mathrm{f}}=3 \times 10^{4} \text { to } 1 \times 10^{5}, \sigma=?, \mathrm{~T} \approx 100^{\circ} \mathrm{C}
$$

These are small-bore, cylindrical tubes under low compressive stresses. The effects of the high $\phi_{\mathrm{ut}} / \phi_{\mathrm{f}}$ ratio is the major uncertainty. Embrittlement is anticipated. Surveillance data from experiments in hydraulic tubes HT- 1 and -3 should remove the uncertainty.

\subsection{THE REFLECTOR VESSEL}

$$
\mathrm{L}=40 \text { years, } \phi \mathrm{t}_{\mathrm{th}}=0.5-1.6 \times 10^{27}, \phi_{\mathrm{th}} / \phi_{\mathrm{f}}=2 \times 10^{4}, \sigma=100(?) \mathrm{Mpa}, \mathrm{T}=125^{\circ} \mathrm{C}
$$

This is the long-term component in the system. Replacement would not be easy and, therefore, a 40-year life is highly desirable. It is not a pressure vessel. The high stress is the result of thermal gradients through the wall thickness. Over the 40 -year life of the vessel, such stresses might cause thermal creep or radiation-assisted creep. Also, they increase the chances of stress-corrosion problems. Swelling will be about $0.5 \%$. The more direct radiation effects concern is embrittlement by the transmutation-produced silicon. Because of the unknown influence of the soft spectrum, the degree of embrittlement is unpredictable. In the absence of evidence to the contrary, it is assumed that the very soft spectrum will inhibit coarsening of the silicon precipitate. The response to thermal fluence will then be greater than that indicated by Fig. 4.4, and the vessel will be embrittled under our embrittlement criteria. The neutron fluxes at the vessel are low, so the damage will build up slowly, and there will be plenty of time to find means of dealing with it if the surveillance programs show that it is, indeed, a problem. However, embrittlement countermeasures and remedies may be difficult or costly to adopt late in the life of the vessel and should be considered now. One option is a replaceable thermal neutron shield to reduce the neutron flux on the vessel. Another is to make allowances in the design for the possibility of performing a dry, in situ, postirradiation anneal on the vessel.

\subsection{SHUTDOWN ROD GUIDES}

$$
\mathrm{L}=2 \text { years, } \phi \mathrm{t}_{\mathrm{th}}=8 \times 10^{26}, \phi_{\mathrm{th}} / \phi_{\mathrm{f}}=320, \sigma=90 \mathrm{Mpa}, \mathrm{T}=120-150^{\circ} \mathrm{C}
$$

This combination of high flux, high $\phi_{\mathrm{u}} / \phi_{\mathrm{f}}$ ratio, high stress, and high temperature is not reassuring for a component whose integrity is necessary for safe operation of the reactor. There are too many 
unknowns. Until more information is available to ease these concerns, caution must be exercised. Reducing the planned service life to 0.5 years as an interim measure would seem advisable. Constructing the guides from a substitute material such as a zirconium alloy, which should be relatively insensitive to the expected fluxes, stresses, and temperature, is under consideration.

\subsection{THROUGH-TUBE}

$$
\mathrm{L}=2 \text { years, } \phi \mathrm{t}_{\mathrm{hh}}=1.8 \times 10^{27}, \phi_{\mathrm{Lh}} / \phi_{\mathrm{f}}=6.4 \times 10^{3}, \sigma=50 \mathrm{Mpa}, \mathrm{T}=125^{\circ} \mathrm{C}
$$

The through-tube is the continuous horizontal beam tube, HB-5/HB-10, that passes below the capped beam tubes. The $\phi_{u} / \phi_{f}$ ratio is much higher than that of the beam tube thimbles (Sect. 5.4). The same comments apply as for the beam tube thimbles.

\subsection{CORE SUPPORT STRUCTURE}

$$
\mathrm{L}=0.5 \text { years, } \phi \mathrm{t}_{\mathrm{ch}}=-5 \times 10^{26}, \phi_{\mathrm{th}} / \phi_{\mathrm{f}}=30, \sigma=40 \mathrm{Mpa}, \mathrm{T}<100^{\circ} \mathrm{C}
$$

It is essential to maintain the integrity of this structure. It is located below the core in the path of the incoming coolant, which should ensure a low temperature. To avoid overexposure, it is planned to replace the structure at 0.5 -year intervals. It will experience moderately high fluences within the range covered in Fig. 4.4. Provided the high $\phi_{\mathrm{th}} / \phi_{\mathrm{f}}$ ratio does not upset the Fig. 4.4 data, no serious radiation problems are expected. 


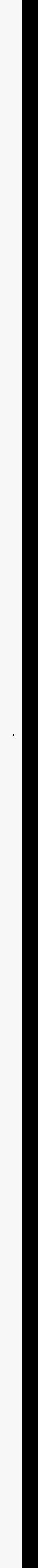




\section{COMMENTS}

Despite the commendable performance of aluminum alloys in research reactors during the past 40 years, there are still many features of their radiation responses that are not understood. The desire to raise service requirements runs afoul of those shortcomings. This review and assessment illuminates the weaknesses and uncertainties in our knowledge and emphasizes the need for continued research and vigilance. In that respect, it cannot be emphasized too strongly that the materials surveillance program planned for $\mathrm{ANS}^{45}$ should be expanded and pursued with vigor. There should be more dedicated surveillance sites at strategic locations in the reactor. In addition to the specified fracture toughness and tensile specimens, the surveillance packages should include TEM disks and flux monitors; microstructural changes and neutron fluxes and spectra are essential for interpreting the surveillance data. As part of this surveillance program, retired components, good and bad, and especially the first ones removed and any for which regular surveillance is lacking, should be tested to determine their degrees of service damage and to build a data base for assessment of remnant lifetimes. Also, whenever a materials test facility in the reactor does not have a payload, it should be filled with surveillance specimens rather than with disposable dummy filler pieces. The results from the surveillance program should be used to assess the program continually and to determine the most economical and safe operating schedules for components.

Recommendation \#4: The materials surveillance program should be expanded as outlined above and should include a formal system for testing retired reactor components.

Welded materials will be included in the surveillance packages. As discussed earlier, welds will degrade the properties of 6061-T6 alloy, and allowances must be made for such degradation. Although welds have not been troublesome in irradiated reactor components, they have received little investigation, and almost nothing is known about their radiation response characteristics. In addition to the previously mentioned softening effects of welding on $\mathrm{T} 6$ material, there is a potential danger from weld flaws. Porosity and cracking are commonly encountered in aluminum welds, especially in thin sections, and are difficult to detect by standard inspection techniques. Radiation hardening will intensify the embrittling effects of such flaws. For these reasons, welds in stressed components must be kept to a minimum. Certainly, the CPBT does not contain welds in its highly stressed central regions. For the reflector vessel, which cannot be constructed without welds, the properties of the welds will define the tolerable stress levels.

Low residual radioactivity of reactor components is a desirable feature for ease of maintenance operations during shutdown periods and for safer disposal of spent components. The 6061 alloy contains minor alloying elements $(\mathrm{Cu}, \mathrm{Zn}, \mathrm{Cr}$, and $\mathrm{Mn}$ ) that generate long-lived activation products. Therefore, there is a proposal to consider substituting the higher-purity alloy $6063(0.7 \mathrm{Mg}, 0.4 \mathrm{Si})$ for some components. Several potential pitfalls are recognized in this proposal. First, the 6063 alloy has only 75\% of the strength of 6061 alloy, and any further removal of the impurities, which control grain size, might further weaken the alloy. Second, it is claimed that the impurities impart aqueous corrosion resistance to the grain boundaries, so removing the impurities might also induce intergranular corrosion problems. These aspects should be explored before a commitment is made to this substitute alloy.

Another proposal is a wire-wrapped, single-wall CPBT. In principle, wrapping the CPBT with multiple (as many as nine) layers of tautly strung, cold-drawn aluminum wire will strengthen it against the hoop stresses imposed by the primary coolant. In practice, a number of drawbacks are perceived. The most important of these are radiation-assisted stress relaxation or recovery of cold work that might thwart the intended strength reinforcement, reduction of heat transfer by the many wire interfaces, 
entrapment of stagnant $\mathrm{D}_{2} \mathrm{O}$ between the wires and encouragement of crevice corrosion, and interference with nondestructive flaw detection. An option might be a laminated, single-wall tube constructed by placing two or three extruded or drawn tubes inside one another and spin-forging them into mutual contact. The fewer interfaces will be less deleterious to heat transfer and will provide crack arrests, perhaps offering extended lifetimes. A shortcoming is that it may be difficult to weld a flange onto a laminated tube of this type. The current design of the CPBT incorporates a flange at its top, through which it is bolted to the top of the RV. Its lower end is unflanged and is held in place with an O-ring seal. If an unflanged CPBT could be used, the laminated tube might provide a relatively inexpensive altemative to the current CPBT design.

The latest design change in the ANS is the adoption of a three-element, annular core in place of the two-element core for which this assessment was made. The three-element core has a larger volume and allows the use of lower-enriched fuel to give the same power as the two-element core with its highly enriched fuel. The larger volume gives lower neutron fluxes and also requires a larger CPBT and an associated outward displacement of some of the components in the reflector. The best neutronics performance for a three-element core is offered by a configuration designated ST-OL2 and composed of two fully overlapped elements located atop the third element, whose diameter is midway between those of the other two. ${ }^{46}$ Compared to the two-element core, the thermal neutron fluxes from the ST-OL2 core are $30-40 \%$ lower in the region within the CPBT and about $15 \%$ lower at the beam tube tips; $\phi_{\mathrm{th}} / \phi_{\mathrm{f}}$ ratios remain high in the reflector regions. From the perspective of radiation damage, these lower fluxes will afford only minor reductions in damage. Therefore, the conclusions drawn from the present assessment of components in the two-element core ANS will hold for the same components in the three-element core ANS. 


\section{REFERENCES}

1. F. J. Peretz, Conceptual Design Summary, ORNL/TM-12184, Martin Marietta Energy Systems, Inc., Oak Ridge Natl. Lab., September 1992.

2. H. R. Voorhees and J. W. Freeman, Report on the Elevated-Temperature Properties of Aluminum and Magnesium Alloys, ASTM STP 291, American Society for Testing and Materials, 1960.

3. Structural Alloys Handbook, Vol. 3, Metals and Ceramics Division Information Center, Batelle Memorial Institute, Columbus, Ohio, 1989.

4. J. E. Dorn and T. E. Tietz, "Creep and Stress-Rupture Investigations on Some Aluminum Alloy Sheet Metals," Proc. Am. Soc. Test. Mater. 49, 815-31 (1949).

5. W. C. Leslie, J. W. Jones, and H. R. Voorhees, "Long-Time Creep Rupture Tests of Aluminum Alloys," J. Test. Eval. 8 (1), 32-40 (1980).

6. T. A. Roach and H. R. Voorhees, "Stress Relaxation of Aluminum Alloys in Tension," in ASME Reports of Current Work on Behavior of Materials at Elevated Temperatures, ed. A. O. Schaefer, Material Properties Council, Inc., New York, 1974.

7. M. J. Manjoine and H. R. Voorhees, Compilation of Stress-Relaxation Data for Engineering Alloys, ASTM Data Series Publications DS60, American Society for Testing and Materials, 1982.

8. G. T. Yahr, "Prevention of Non-Ductile Fracture in 6061-T6 Aluminum Nuclear Pressure Vessels," pp. 156-67 in International Pressure Vessel Piping Codes and Standards, Vol. 1, Current Applications, presented at the ASME/JSME Conference, Honolulu, July 23-27, 1995.

9. F. G. Nelson and J. G. Kaufman, "Plane Strain Fracture Toughness of Aluminum Alloys at Room Temperature and Subzero Temperatures," pp. 27-39 in Fracture Toughness Testing at Cryogenic Temperatures, ASTM STP 496, American Society for Testing and Materials, 1971.

10. D. J. Alexander, "Materials for Cold Neutron Sources: Cryogenic and Irradiation Effects," pp. 321-41 in Proceedings of International Workshop on Cold Neutron Sources, Los Alamos, New Mexico, March 5-8, 1990, LA-12146-C/UC-413, Los Alamos National Laboratory, August 1991.

11. G. T. Yahr, "Fatigue Design Curves for 6061-T6 Aluminum," pp. 43-49 in Codes and Standards in a Global Environment, ASME PVP, Vol. 259, American Society of Mechanical Engineers, New York, 1993.

12. "Use of 6061-T6 and 6061-T651 Aluminum for Class 1 Nuclear Component, Section III, Division 1," Cases of Boiler and Pressure Vessel Code, American Society of Mechanical Engineers, New York, 1992; Supplement 10-NC, 1994, Case N-519. 
13. R. P. Martukanitz, "Selection and Weldability of Heat-Treatable Aluminum Alloys," pp. 528-36 in Welding Brazing and Soldering, ASM Handbook, Vol. 6, ASM International, Metals Park, Ohio, 1992.

14. J. Bucholz, Initial Global 2-D Shielding Analysis for the ANS Core and Reflector, ORNL/TM-12672, Lockheed Martin Energy Systems, Inc., Oak Ridge Natl. Lab., July 1995.

15. T. A. Gabriel, B. L. Bishop, and F. W. Wiffen, Calculated Irradiation Response of Materials Using Fission Reactor (HFIR, ORR, and EBR-II) Neutron Spectra, ORNL/TM-6361, Union Carbide Corp., Oak Ridge Natl. Lab., August 1979.

16. K. Farrell, J. O. Stiegler, and R. E. Gehlbach, "Transmutation-Produced Silicon Precipitates in Irradiated Aluminum," Metallography 3, 275-84 (1970).

17. R. T. King, A. Jostsons, and K. Farrell, "Neutron Irradiation Damage in a Precipitation-Hardened Aluminum Alloy," pp. 165-80 in Effects of Radiation on Substructure and Mechanical Properties of Metals and Alloys, ASTM-STP 529, American Society for Testing and Materials, 1973.

18. K. Farrell and A. E. Richt, "Postirradiation Properties of the 6061-T6 Aluminum High Flux Isotope Reactor Hydraulic Tube," p. 311-25 in Properties of Reactor Structural Alloys After Neutron or Particle Irradiation, ASTM-STP 570, American Society for Testing and Materials, 1975.

19. K. Farrell and R. T. King, "Tensile Properties of Neutron-Irradiated 6061 Aluminum Alloy in Annealed and Precipitation-Hardened Conditions," pp. 440-49 in Effects of Radiation on Structural Materials, ASTM-STP 683, American Society for Testing and Materials, 1979.

20. J. R. Weeks, C. J. Czajkowski, and P. R. Tichler, "Effects of High Thermal and High Fast Fluences on the Mechanical Properties of Type 6061 Aluminum in the HFBR," pp. 441-52 in Effects of Radiation on Materials: 14th International Symposium, Vol. II, ASTM-STP 1046, American Society for Testing and Materials, 1990.

21. J. R. Weeks, C. J. Czajkowski, and K. Farrell, "Effects of High Thermal Neutron Fluences on Type 6061 Aluminum," pp. 1168-82 in Effects of Radiation on Materials: 16th International Symposium, ASTM-STP 1175, American Society for Testing and Materials, 1993.

22. R. V. Steele and W. P. Wallace, "Effect of Neutron Radiation on Aluminum Alloys," Metal Progress 68, 114-15 (1955).

23. H. E. McCoy, Jr. and J. R. Weir, Jr., "Influence of Irradiation on the Tensile Properties of the Aluminum Alloy 6061," Nucl. Sci. Eng. 25, 319-27 (1966).

24. H. D. Gronbeck, ETR Radiation Damage Surveillance Programs, Progress Report II, IN-1036, Idaho Nuclear Corporation, Idaho Falls, Id., February 1967.

25. J. G. Y. Chow and R. Jones, Review of HFBR Surveillance Program, memorandum, Brookhaven National Laboratory, Upton, N.Y., July 12, 1976. 
26. D. J. Alexander, "The Effect of Irradiation on the Mechanical Properties of 6061-T651 Aluminum," pp. 1151-67 in Effects of Radiation on Materials: 16th International Symposium, ASTM-STP 1175, American Society for Testing and Materials, 1993.

27. M. F. Marchbanks, ANS Materials Databook, ORNL/M-4582, Lockheed Martin Energy Systems, Inc., Oak Ridge Natl. Lab., August 1995.

28. D. J. Alexander, Monthly Progress Report for June 1994, Attachment 9, ORNL/ANS/INT-5/V75, Martin Marietta Energy Systems, Inc., Oak Ridge Natl. Lab., August 1994.

29. M. I. de Vries and M. R. Cundy, "Results from Post-Mortem Tests with Material from the Old Core Box of the High Flux Reactor (RHF) at Petten," pp. 1-9 in International Symposium on Research Reactor Safety, Operations and Modifications, IAEA-SM-310/69P, International Atomic Energy Agency, Vienna, 1989.

30. K. Farrell, “A Spectral Effect on Phase Evolution in Neutron-Irradiated Aluminum?" pp. 165-70 in Microstructure of Irradiated Materials, Symposium Proceedings, Vol. 373, Materials Research Society, Boston, 1994.

31. A. L. Lotts et al., Analysis of Failure of HFIR Target Elements Irradiated in SRL and in HFIR: An Interim Status Report, ORNL-TM-2236, Union Carbide Corp., Oak Ridge Natl. Lab., February 1972.

32. K. Farrell, "ORNL Studies of Radiation Damage in Aluminum and Its Alloys: A Status Report," internal correspondence, Union Carbide Corp., Oak Ridge Natl. Lab., December 1973.

33. R. T. King, K. Farrell, and A. E. Richt, "Creep Properties of Irradiated Aluminum Alloys from the HFIR Surveillance Program," Nucl. Metall. 19, 133-52 (1973).

34. E. R. W. Jones, W. Munro, and N. H. Hancock, "The Creep of Aluminium During Neutron Irradiation," J. Nucl. Energy 1, 76-86 (1954).

35. S. Sh. Ibragimov, E. S. Aitkhozhin, and Y. S. Pyatiletov, "Radiation-Induced Creep of Aluminum and Copper," pp. 5-10 in Influence of Radiation on Materials Properties: 13th International Symposium, Part II, ASTM-STP 956, American Society for Testing and Materials, 1987.

36. R. D. Cheverton and J. R. McGuffey, Analysis of HFIR Bearing Mount Failures and Design of the Set VI Mounts, ORNL Central Files No. 68-8-53, Oak Ridge Natl. Lab., Aug. 30, 1968.

37. L. Albertin and J. DeMastry, Post-Irradiation Tensile and Fracture Toughness Properties of 6061T651 Aluminum Plate, Westinghouse Astronuclear Laboratory, Pittsburg, 1972.

38. MM. Astruc, Harig, Sauvigne, and Verdier, Source Froide Du Reacteur a Haut Flux; Projet de Realisation and Rapport de Surete, AL 91 PCBT 69/1186, Institut Laue-Langevin, Grenoble, France, December 1969. 
39. W. Lohmann, A. Ribbens, W. F. Sommer, and B. N. Singh, "Microstructure and Mechanical Properties of Medium Energy (600-800 MeV) Proton Irradiated Commercial Aluminum Alloys," Radiat. Eff. and Defects in Solids 101, 283-99 (1986).

40. Z. H. Ismail, "Effect of Low Neutron Irradiation on the Mechanical Properties of an AlMgSi Alloy," Radiat. Eff. and Defects in Solids 112, 105-10 (1990).

41. Z. H. Ismail and B. Birt, "Post-Irradiation Mechanical Properties of an AlMgSi Alloy," J. Nucl. Mater. 218, 289-92 (1995).

42. H. Yoshida, T. Kozuka, and T. Sagane, "Reactor Irradiation Effects on Al 1100," pp. 1-6 in Proceedings of the 24th Japan Congress on Materials Research-Metallic Materials, Kyoto University, 1981.

43. A. Munitz, "Neutron Irradiation Effects on Commercial Purity Type A5 Aluminum," J. Nucl. Mater. 165, 305-12 (1989).

44. O. S. Oen and D. K. Holmes, "Cross Sections for Atomic Displacements in Solids by Gamma Rays," J. Appl. Phys. 30 (8), 1289-95 (1959).

45. S. M. Heavilin, Advanced Neutron Source Materials Program, ORNL/M-3733, Martin Marietta Energy Systems, Inc., Oak Ridge Natl. Lab., August 1994.

46. J. C. Gehin, Neutronic Analysis of Three-Element Core Configurations for the Advanced Neutron Source Reactor, ORNL/TM-12967, Lockheed Martin Energy Systems, Inc., Oak Ridge Natl. Lab., July 1995. 


\section{INTERNAL DISTRIBUTION}

1. D. J. Alexander

2. D. F. Craig

3-5. K. Farrell

6. G. F. Flanagan

7. L. K. Mansur

8. T. J. M9Manamy

9. C. C. Queen

10. D. L. Selby
11. C. D. West

12. G. T. Yahr

13. ORNL Patent Office

14. Central Research Library, Document Reference Section

15-16. Laboratory Records

17. Laboratory Records (RC)

18-19. M \& C Records Office

\section{EXTERNAL DISTRIBUTION}

20. U.S. Department of Energy, ANS Project Office, Oak Ridge Operations Office, FEDC, MS-8218, P.O. Box 2009, Oak Ridge, TN 37831-8218.

21-22. Office of Scientific and Technical Information, P.O. Box 62, Oak Ridge, TN 37831. 
